\title{
LOS CONFLICTOS AMBIENTALES EN CUBA, SOLUCIÓN DENTRO DEL DERECHO INTERNO. SU TRATAMIENTO TEÓRICO DOCTRINAL EN OTROS SISTEMAS DE DERECHO COMPARADO.
}

\author{
ALCIDES FRANCISCO ANTÚNEZ SÁNCHEZ ${ }^{1}$. \\ CARLOS JUSTO BRUZÓN VILTRES ${ }^{2}$.
}

\begin{abstract}
Recibido el 28 de agosto de 2012 y aprobado el 1 de diciembre de 2012
\end{abstract}

\section{RESUMEN}

El presente trabajo es el resultado de investigaciones sobre la temática por parte de los autores, en relación con la protección de los animales, la responsabilidad ambiental, y con ella la problemática ambiental, tomando como muestra el resultado de la inacción en la solución de los conflictos ambientales como resultados de acciones de control ejecutadas en el territorio de la provincia Granma; el problema científico se enfoca en demostrar la inacción por parte de los entes y agentes que con jurisdicción y competencia están facultados para aplicar la legislación en materia de medio ambiente. Para la conformación del artículo se utilizaron diversos trabajos de investigación sobre la temática con una visión epistemológica sobre el tema objeto de investigación, lo que permitió abordar la muestra a partir de los años 2006 hasta el 2010, dándole continuidad permitiendo demostrar que la inacción de la conflictividad ambiental aún persiste. Se utilizó como métodos para realizar la investigación el exegético-jurídico, el jurídico-comparado, el histórico-lógico, el análisis-síntesis, y el inductivo-deductivo, que han permitido llegar a las conclusiones en este informe, para poder demostrar la necesidad de reformar la actual legislación ambiental en materia de responsabilidad ambiental.

\section{PALABRAS CLAVE}

Medio ambiente, conflictos ambientales, tribunal ambiental, responsabilidad ambiental.

\section{ENVIRONMENTAL CONFLICTS IN CUBA, A SOLUTION INSIDE THE INTERNAL LAW. THEIRTHEORETICAL-DOCTRINAL TREATMENT IN OTHER COMPARATIVE LAW SYSTEMS}

\section{ABSTRACT}

This work is the result of investigations on the subject matter by the authors in relation to animal protection, environmental responsibility, and with it, environmental problems, taking as a sample the result of the inaction in the solution of environmental conflicts as the result of actions of control executed in the territory 
of the Granma province. The scientific problem focuses on demonstrating the inaction on the entities and agents part who, with jusridiction and competence, are authorized to apply the legislation on environment. For the conformation of the article, various research works on the subject matter with an epistemological vision on the theme were used, which allowed to tackle the sample from 2006 to 2010 , giving it continuity and allow demonstrating how inaction of environmental conflictive situation still persists. The methods used to accomplish the investigation were the exegetic juridical method, the juridical comparative method, the historic logical method, the analysis synthesis method, and the inductive deductive method, which have allowed to come to the findings in this report in order to be able to demonstrate the need to reform the present-day environmental legislation on the subject of environmental responsibility.

\section{KEY WORDS}

Environment, environmental conflicts, environmental court, environmental responsibility.

\section{INTRODUCCIÓN}

Hace algunos miles de años, antes de que el hombre imprimiese su propia huella, el paisaje de la tierra se caracterizaba por la presencia de grandes masas de vegetación, no existía la contaminación y el agua era abundante y limpia, en la actualidad esta historia dista mucho de lo real, existe una estrecha relación entre las cuestiones económicas y medioambientales que se condicionan de manera muy notable, ya que el desarrollo de las sociedades y su adaptación evolutiva dependen en gran medida de la utilización de los recursos que existen en la naturaleza, por tanto, la protección del medio ambiente ya no resulta un lujo o un capricho, sino que es una de las claves para el desarrollo futuro y la permanencia de la sociedad; no se trata sólo de proteger al medio ambiente en sí sino la supervivencia y el desarrollo sostenible de la humanidad a medio y largo plazo, además de una demanda social en cuanto a los derechos de la salud y determinados estándares de calidad de vida. [1].

Va quedando lejana en el tiempo la discusión, carente de mucho sentido práctico, acerca de sí la conjunción de los vocablos "medio" y "ambiente" da origen o no a un término redundante en sí mismo. [2]. Lo cierto es que este concepto ya ha adquirido plenos créditos y por tanto en este trabajo se empleará continuamente, lo cual demanda la necesidad de brindar al respecto una definición integral y coherente. El medio ambiente puede ser conceptualizado de diversos modos. Una primera aproximación nos lleva a pensar en los elementos básicos de la vida en la tierra, es decir, el suelo, el agua, la atmósfera y las formas vivas que estos elementos 
albergan. Tal concepción, si bien no es errónea, no resulta completa, en tanto no incluye las interacciones de estos elementos entre sí y con el hombre en particular.

Pero es que hay más, en este proceso de accionar recíproco, donde el hombre desempeña un rol protagónico, surgen nuevos componentes del ambiente, de carácter histórico, cultural, social y estético. Se trata de lo que se ha dado en llamar el "medio ambiente construido". De este modo, el medio ambiente resulta el "mundo exterior", pero no un mundo independiente del sujeto a partir del cual se analiza, sino en constante interrelación con el mismo, formando un todo sistemático. Desde que el hombre existe sobre la faz de la tierra, ha estado interactuando con el medio ambiente, modificándolo de muy diversos modos. Se considera que con el uso del fuego el hombre produjo el primer cambio ambiental de importancia, al exterminar plantas locales de insuficiente resistencia y estimular el crecimiento de otras. La agricultura y la ganadería constituyeron también una importante fuente de cambios en el medio ambiente. Empero, como con razón se apunta [3].

[...] no habría cuestión ambiental alguna, si los recursos del Planeta fueren infinitos o si, en tal caso, no se dependiera de ellos para la subsisten $\neg$ cia; lamentable $\urcorner$ mente no es esa la situación y es por ello que devienen los conflictos con el ambiente.

La Ley número 33 de 10 de enero de 1981, "De Protección del Medio Ambiente y del Uso Racional de los Recursos Naturales", Ley Marco del medio ambiente en Cuba, definió el medio ambiente como: "[...] el sistema de elementos abióticos, bióticos y socioeconó $\neg$ micos con el que interactúa el hombre, a la vez que se adapta al mismo, lo transforma y lo utiliza para satisfacer sus necesidades." (Artículo 2) Se considera este concepto básicamente acertado, en tanto cumple los prerrequisitos que mentamos, al propio tiempo apuntamos que el mismo ha sido desarrollado en la Resolución número130 de primero de junio de 1995, del Ministerio de Ciencia, Tecnología y Medio Ambiente, contentiาva del "Reglamento para la inspección ambiental estatal" la cual, respetando el inicio de la expresión, añade, "[...] lo transforma y lo utiliza de manera sosteni- ble para satisfacer sus necesidades" (Artículo 2, quinta pleca)..[4] La Ley número 81 de 11 de julio de 1997, "Del Medio Ambiente", que derogara la Ley número 33 y constituye la actual norma marco en esta esfera, reitera, con algún ligero cambio gramatical, el concepto de la Ley número 33. La exclusión de la referencia a la utilización "desarrollo sostenible", obedece a una enconada discusión que tuviera lugar durante el proceso de elaboración y conciliación de la Ley, cuyo fundamento radicaba en cuestionar si era posible referirse a un uso sostenible de los recursos naturales no renovables. En los intercambios prevaleció el criterio - discuti $\neg$ ble- de que no era aceptable hablar de sostenibilidad en este contexto. Es por esa razón que salvo alguna excepción, el concepto de sostenibilidad en 
la Ley se ve constreñido a conjugarse con la idea del desarrollo. La soberanía del Estado abarca a plenitud el medio ambiente y los recur?sos naturales, tanto vivos como no vivos, sobre todo el territo ᄀrio nacional, así lo expresa el artículo 11 de la Constitución el cual dispone el ejercicio de estos derechos soberanos:

a) Sobre todo el territorio nacional, integrado por la isla de Cuba, la Isla de la Juventud, las demás islas y cayos adyacentes, las aguas territoriales y el mar territorial en la extensión que fija la ley y el espacio aéreo que sobre estos se extiende; b) sobre el medio ambiente y los recursos naturales del país; c) Sobre los recursos naturales, tanto vivos como no vivos, de las aguas, el lecho y el subsuelo de la zona económica marítima de la República, en la extensión que fija la Ley conforme a la práctica internacional."[5].

Por su parte, el Artículo 2 de la Ley número 81 dispone que:

[...] el medio ambiente es patrimonio e interés fundamental de la nación. El Estado ejerce su soberanía sobre el medio ambiente en todo el territorio nacional y en tal sentido tiene el derecho de aprovechar los recursos que lo componen según su política ambiental y de desarrollo.

\section{Y continúa afirmando por su Artículo 3 que:}

Es deber del Estado, los ciudadanos y la sociedad en general proteger el medio ambiente mediante: a) Su conservación y uso racional; b) La lucha sistemática contra las causas que originan su deterioro; c) Las acciones de rehabilitación correspondientes; d) EI constante incremento de los conocimientos de los ciudadanos acerca de las interrelaciones del ser humano, la naturaleza y la sociedad. e) La reducción y eliminación de las modalidades de producción y consumo ambientalmente insostenibles; f) El fomento de políticas demográficas adecuadas a las condicio $\urcorner$ nes territoriales.

Hasta el presente siglo, las normas jurídicas dirigidas a la protección de algún componente de lo que hoy entendemos como medio ambiente, se caracterizaban por ser exiguas, dispersas y marcadas por un fuerte carácter utilitario. Si bien las leyes, que son hechas por y para los hombres, no pueden escapar de una tendencia antropocentrista; tiene que comprenderse que esta óptica, en cuanto a los componentes del medio ambiente se refiere, debe ser supeditado al reconocimiento de sus valores intrínsecos y por tanto, al deber inalienable a ser conservado y utilizado de forma sostenible [6] independientemente de la utilidad que el hombre vea en algunos de ellos. Como han reconocido otros autores, aún en los felices casos en que una especie era protegida, no lo era siempre su hábitat y se excluían de la tutela jurídica el resto de los reinos de la diversidad biológica no comprendidos en los de Animalia y Plantae [7] y que conforme al 
momento se caracterizaban como útil, lo que constituía un contrasentido. Esto demostraba la ausencia de un enfoque sistémico al abordar la conservación de algún componente del medio ambiente, lo que no puede atribuirse sólo a la falta de conocimientos científicos más profundos y acabados, sino a la existencia de fuertes intereses mercantilistas en las relaciones sociales y que marcaron su impronta en el vínculo, hombrenaturaleza. La idea prevaleciente en las ciencias naturales en la primera mitad del Siglo XVIII, era la de la inmutabilidad de la Naturaleza. La historia de la civilización era vista con un pasado, un presente y un futuro, en que los acontecimientos se sucedían en el tiempo, sin embargo, la naturaleza era observada como un ente imperturbable, y estático. [8]. Reflejo de los conocimientos elementales de las ciencias de la época, que no permitían un análisis holístico de la naturaleza.

La tarea principal...de las ciencias naturales [...] consistía en dominar el material que se tenía a mano. En la mayor parte de las ramas hubo que empezar por lo más elemental. La química acababa de liberarse de la alquimia [...] La geología aún no había salido del estado embrionario que representaba la mineralogía y por ello la paleontología no existía aun. Finalmente en [...] la biología la preocupación era [...] la acumulación y clasificación de un inmenso acervo de datos no sólo botánicos y zoológicos, sino también anatómicos. Casi no podía hablarse aun de la comparación de las distintas formas de vida, ni de los estudios de su distribución geográfica, condiciones climatológicas y demás condiciones de existencia. [9].

Otra era la posición de la filosofía, que se esforzó tenazmente para explicar el mundo partiendo del mundo mismo un ejemplo fue Holbach, (1723-1789) enciclopedista francés, el que en su obra "Sistema de la Naturaleza" alertaba:

El hombre ha sido la obra de la naturaleza, no existe más que en ella y es regido por sus leyes, [...] Para un ser creado por la naturaleza y sometido a ella, nada existe fuera del conjunto o todo, del que forma parte, y que recibe toda especie de influencias.

Estas palabras de Holbach fueron dichas en un momento en que el desarrollo alcanzado por las ciencias y los conocimientos acumulados por el hombre no habían permitido elaborar un concepto más abarcador del entorno en que se desenvolvía la vida del mismo, que no fuera -Naturaleza- expresión que define el conjunto de los seres vivos, y hacia la cual el hombre ha mantenido una relación, rodeada a veces de una aureola mística, ideal o de franco respeto, como es el caso del filósofo francés, hacia este todo, no totalmente entendido ni conocido del que viene la vida. [10]. Debemos apreciar que la esencia de ese planteamiento tiene plena vigencia, es la estrecha interrelación que guarda el hombre con el medio que lo rodea, con su entorno, con el sistema de organismos bióticos, abióticos y emocionales en que 
está insertado. En el DRAE [11] se expresa esta definición como: "se entienden por medio ambiente el conjunto de circunstancias físicas, culturales, económicas y sociales que rodean a las personas y a los seres vivos". Por otra parte, si analizamos las normas técnicas ambientales ISO 14 001, se establece tal definición como "el entorno en el cual una organización opera, incluyendo el aire, el agua, la tierra, los recursos naturales, la flora, la fauna, los seres humanos y sus interrelaciones". [12] Por lo que se infiere a modo de una primera conclusión que todas estas definiciones implican directamente al hombre, su actividad, su interacción con el medio, y presentan al medio ambiente como el entorno necesario para la vida o el conjunto de factores que interaccionan entre sí y con el factor tiempo.

\begin{tabular}{|l|l|}
\hline $\begin{array}{l}\text { Fuente de } \\
\text { recursos } \\
\text { naturales }\end{array}$ & $\begin{array}{l}\text { Ya que proporcional al ser humano las materias primas y la } \\
\text { energía necesaria para la vida y su desarrollo }\end{array}$ \\
\hline $\begin{array}{l}\text { Soporte de } \\
\text { actividades }\end{array}$ & Ya que acoge el conjunto de actividades desarrolladas \\
\hline $\begin{array}{l}\text { Receptor de } \\
\text { efluentes }\end{array}$ & $\begin{array}{l}\text { Porque recibe todas las emisiones, vertidos y residuos } \\
\text { procedentes de las actividades desarrolladas por el hombre }\end{array}$ \\
\hline \multicolumn{2}{|c|}{ Tipos de recursos } \\
\hline $\begin{array}{l}\text { Recursos } \\
\text { renovables }\end{array}$ & $\begin{array}{l}\text { Aquellos que se reproducen o regeneran y son por tanto } \\
\text { inagotables }\end{array}$ \\
\hline $\begin{array}{l}\text { Recursos no } \\
\text { renovables }\end{array}$ & Aquellos que tienen una existencia limitada, es decir se agotan \\
\hline
\end{tabular}

Fuente: Manual para la formación en medio ambiente. España.

En el Siglo XIX, la Geología nos mostró no sólo las edades geológicas de la tierra sino aquellos huéspedes no parecidos a los que nos acompañan hoy y que demostraron al hombre que la naturaleza está sujeta a cambio, a un constante nacer y morir [13]. El Derecho como elemento de la superestructura, como rasgo del Estado y el derecho, no estuvo ajeno a estas realidades, no podía ser de otra forma, el desarrollo económico del siglo XIX, marcado por una burguesía en ascenso, ávida de recursos naturales, las limitaciones de las ciencias naturales que no permitían un estudio sistémico de la naturaleza y el hecho real de que la misma era capaz de enfrentar y restablecerse de los daños o impactos ambientales, marcó el hecho de que la legislación del momento estuviera dirigida a asegurar la explotación de la flora y la fauna mientras su protección se mantuviera dentro de los límites de las utilidades, ejemplo significativo del enfoque utilitario en nuestro país fue la "Ley de Caza" de 1884, puesta en vigor por Real Decreto de 31 de junio del propio año, que parte de lo útil que era para la agricultura una especie para disponer su protección. llustraban esta posición dos apéndices contenidos en la propia ley, uno donde se relacionaba los animales útiles y que debían de ser protegidos, P. ej. El cernícalo y la lechuza; otro referido a animales dañinos como la cotorra, el guacamayo y el sinsonte. Similares derroteros mantiene nuestra legislación en la primera mitad del actual siglo y de lo cual es un ejemplo entre otros la "Ley de Caza 
y Pesca" de 1909 que derogó la de 1884; esta mantuvo su filosofía utilitaria y el lugar que ocupaban las mismas especies en los apéndices, era bien diferentes, la lechuza y el cernícalo eran dañinos mientras la cotorra, el guacamayo y el sinsonte eran útiles.

La Ley de Caza de 1909, fue modificada en 1928, sin aportar nada significativo. Hubo normas jurídicas que de alguna forma estuvieron dirigidas a la protección de determinada especie en peligro de extinción o amenazada, como fueron los casos por ejemplo del Decreto número 1164 de 14 de junio de 1928 que suspendió por un período de dos años la caza de la paloma rabiche, el Decreto número 844 de 24 de junio de 1930 que declaró la veda permanente de la paloma torcaza y el guacamayo, entre otras aves, y el Decreto número 203 de 1ro de junio de 1928 que establece el Refugio Nacional para Flamingos. Pero la falta de voluntad política y conciencia ciudadana para su cumplimiento hicieron que se convirtieran en muchos casos en letra muerta. Lo útil que le podamos encontrar a un componente del medio ambiente, como consecuencia del nivel de los conocimientos científicos acertados o no, completos o no y del nivel de desarrollo económico logrado, no pueden ser el indicador a tener en cuenta al momento de trazar políticas ambientales y legislar. Analizando nuestra actitud frente al medio ambiente, nos percatamos que la toma de conciencia que de forma creciente se advierte hoy en el mundo sobre este tema, no es más que la respuesta a la que nos hemos visto enfrentados, por el olvido centenario que hicimos de nuestra condición de integrantes de este todo, al que se refería Holbach. (s.f) "Lo particular no existe más que en la relación que lleva a lo general. Lo general existe únicamente en lo particular, mediante lo particula" r[14]. Ninguna especie, incluida la nuestra, el Homo Sapiens, tiene sentido -posibilidad de existencia-, sino es insertada dentro de la naturaleza, sino es en una relación con lo general -la naturaleza-, la que a su vez se expresa de una forma u otra, en las características propias, esenciales, particulares de cada especie de cada individuo, en ello tenemos una razón para respetar y conservar la diversidad biológica independientemente de la visión esquemática, superficial y pragmática de su utilidad, todos somos, independientemente de nuestra voluntad una expresión palpitante de lo general, de la naturaleza.

El primer mundo ha impuesto un esquema de desarrollo, marcado por el desprecio a todo aquello que no sea multiplicador de ganancias y un abuso desmedido en el uso y disfrute de los recursos naturales, lo que hoy se denomina brecha económica, en todos los casos, sea por autoría intelectual de las tecnologías o los esquemas de desarrollo o por provocarlos objetivamente, los daños a la naturaleza y al medio ambiente, como concepto más abarcador, comenzó por ellos, y cuando los daños llegaron a sus territorios fue cuando comenzaron a preocuparse. Se dieron cuenta que no importa que seas rico o pobre, las afectaciones al medio ponen en peligro la vida de todos por igual no nos dejemos llevar del entusiasmo ante nuestras victorias sobre la naturaleza, 
después de cada una de estas victorias la naturaleza toma sus ventajas. Bien es verdad que la primera consecuencia de esta victoria son las previstas por nosotros, pero en segundo lugar y en tercer lugar aparecen unas consecuencias muy distintas, totalmente imprevistas [15]. Atenta a la necesidad de unos criterios y unos principios comunes que ofrecieran a los pueblos del mundo la inspiración y guía necesaria para preservar y mejorar el medio humano, se reunió en Estocolmo del 5 al 16 de junio 1972, la Conferencia de las N.N.U.U. sobre "Medio Humano". Somos del criterio de que el nombre de dicho evento "Medio Humano", no es fortuito. Si leemos con detenimiento la Declaración de Estocolmo vemos una fuerte tendencia antropocéntrica, de los 26 principios, sólo tres (los principios 4, 6 y 7) se refieren de una forma tímida a los ecosistemas, a la flora y la fauna. En particular, el principio Número. 4 expone: "El hombre tiene la responsabilidad especial de preservar y administrar juiciosamente el patrimonio de la flora y la fauna [...].En otro momento dicho principio se refiere a la planificación racional, ambos términos adolecen de una gran dosis de subjetivismo. Racional y juicioso fue para Felipe II en 1577 su disposición de que le fueran enviados los mejores ejemplares de cedro, ébano y caoba, que hoy lucen transformados por el arte en el monumental retablo del Coro del Escorial [16]; racional y juiciosa fue para los terratenientes criollos la comunicación enviada por el Real Consulado de La Habana al Soberano en 1798, en que expresaban que los montes cubanos eran inagotables por mucho que se talasen y que era materialmente imposible que el desmonte ejecutado por los particulares pudiese acabar con ellos, a raíz de una disposición del gobierno que prohibió la explotación de los mismos por los particulares para que fueran aprovechadas sus maderas por la marina [17], ya a mediados del Siglo XIX Alejandro de Humboldt, apuntaba que la isla se había despoblado de arboles por la excesiva cantidad de terreno que se han desmontado [18]. La racionalidad y el juicio, en este terreno, responden a condiciones objetivas y subjetivas, cambiantes en extremo, y que por tanto no pueden ser el rasero que imponga la medida de hasta dónde se puede utilizar por el hombre un recurso natural, los hechos posteriores a Estocolmo, demostraron no sólo la poca efectividad de estos conceptos al momento de legislar trazar políticas y educar, sino además la ausencia de acciones reales y concreta por parte de los gobiernos para enfrentar y solucionar, por encima de interés egoístas los problemas ambientales que ponían en peligro la vida sobre el planeta. Aunque significó sin lugar a dudas, un paso de avance en la lucha por el logro de una conciencia ambientalista en el mundo, sin embargo los hechos posteriores demostraron que lo analizado en Estocolmo no fue suficiente y el medio ambiente continuo siendo agredido.

- En 1984, un grupo de científicos alemanes detecto signos de deterioro en los bosques y aunque ya era ampliamente conocido el hecho de que la lluvia ácida podía llegar a dejar lagos de agua pura sin rastros de vida, la idea de que 
también podía causar un daño generalizado a los bosques era nueva.

- La tierra perdía 11 millones de hectáreas de bosque cada año en 1983 la cifra es de 17 millones, el territorio de la India en el decenio

- En 1985, dos científicos británicos informaban de hallazgo de un agujero de ozono sobre la Antártida [19].

En 1987 la preocupación del mundo ante el deterioro del medio ambiente llevó a la Asamblea General de las Naciones Unidas a acoger por Resolución el establecimiento de una Comisión que elaboraría un informe sobre el Medio ambiente hasta el año 2000. El 16 de junio de 1987 el consejo de administración del Programa de Naciones Unidas para el Medio Ambiente y el Desarrollo (PNUD) adoptó la decisión de remitir a la asamblea general de las NN. UU el Informe de la Comisión Mundial sobre el Medio Ambiente y el Desarrollo, conocido como Nuestro Futuro Común [20], conocido también como Informe Brundtland por haber sido presentado por la Sra. Gro Harlem Brundtland, Primera Ministra Noruega en aquel entonces [21], el que en su preámbulo nos expresa que el medio ambiente no existe como una esfera separada de las acciones humanas, las ambiciones y demás necesidades y las tentativas para definirlas aisladamente de las preocupaciones humanas, han hecho que la palabra propia de "medio ambiente" adquiera una connotación de ingenuidad en algunos círculos políticos. La palabra "desarrollo" también ha sido reducida por algunos a una expresión muy limitada, algo así como "que las naciones pobres deberían hacer para convertirse en ricas". Pero el medio ambiente es donde vivimos todos, y el desarrollo es lo que todos hacemos al tratar de mejorar nuestra suerte en el entorno en que vivimos. A mediados del siglo XX, vemos nuestro planeta por primera vez desde el espacio;

[...] Desde el espacio vemos una esfera pequeña y frágil, dominada no por la actividad y las obras humanas, sino por un conjunto de tierra, océano y espacios verdes, la incapacidad humana de encuadrar su actividad en ese conjunto está modificando, fundamentalmente el sistema planetario.

Casi a doscientos años del alerta de Holbach, el Informe Brundtland nos recordaba que no debemos perder de vista el lugar que ocupamos, como un componente más del medio ambiente, si bien fundamental por los impactos significativos que estamos en capacidad de efectuar sobre él. Dentro de sus objetivos se encontraba el proponer una estrategia medio ambiental a largo plazo para alcanzar un desarrollo sostenible, o sea, el "asegurar que se satisfagan las necesidades del presente sin comprometer la capacidad de la futuras generaciones para satisfacer las propias" oportunidad que el Informe expresa que debe alcanzar a todos los seres humanos 
[...] la satisfacción de la necesidades esenciales exige no sólo una nueva era de crecimiento económico para las naciones donde los pobres constituyen la mayoría, sino la garantía de que estos pobres recibirán, las partes que le corresponden de los recursos necesarios para satisfacer este crecimiento [...]

El desarrollo duradero no es un estado de armonía sino un proceso de cambio por el que la explotación de los recursos, la dirección de las inversiones, la orientación de los progresos tecnológicos y las modificaciones de las instituciones se vuelven acorde con las necesidades presentes también como futuras [22]. La definición de desarrollo sostenible expuesta en el Informe no da lugar a dudas, explica en contenido, las metas y el cómo lograrlo. No son los accidentes puntuales que han afectado gravemente ecosistemas específicos, como puede ser el derrame de petróleo en el mar por la colisión de un buque o de fallas en instalaciones petroleras, las que han marcado el signo de alarma para la existencia de vida en el planeta, sino los efectos acumulativos de varios procesos globales, consecuencia fundamentalmente de modelos de desarrollo económicos, marcados por un desprecio hacia todo aquello que no reporte riqueza material y utilitarismo. Cuatro grandes factores globales están poniendo en peligro la vida sobre el planeta y han sido la llamada de atención, sobre otros que son menos evidentes o dramáticos, pero que marcan la necesidad de un enfoque sintético en el análisis del medio ambiente:

Disminución de la capa de ozono y la incidencia directa de los rayos ultravioletas en la salud humana, lo que ocasiona la pérdida del equilibrio inmunológico, el aumento del cáncer, la ceguera y otras aflicciones cutáneas. Las causas hay que buscarlas en los gases compuestos por cloro, flúor y carbonato, que se utilizan como refrigerantes, aerosoles y solventes, para fabricar plásticos.

Efecto invernadero, se vaticina un aumento del clima entre $1.5 \mathrm{y}$ 4.5. Grados centígrados, en los comienzos del próximo milenio. De no controlarse la emisión de gases contaminantes provenientes de los combustibles fósiles, la "boina de plástico" producida por la contaminación del bióxido de carbono amenaza con propiciar el derretimiento de los casquetes polares, el hundimiento de las costas de bajo nivel del mar y la multiplicación de los desiertos improductivos.

Deforestación de las selvas tropicales y la pérdida de medio ambiente, si bien aquellos cubren sólo el $6 \%$ de la superficie terrestre, contiene por lo menos la mitad de las especies de la flora y la fauna terrestre. La deforestación contribuye a agravar el deterioro de los recursos de agua dulce.

Desecho, las industrias no saben qué hacer con la basura y en especial las toxinas están acudiendo a los países pobres para que les sirva de basura atómica o de residuales peligrosos. Los 
desechos industriales han destruido la vida acuática en gran parte de los lagos y ríos; el agua contaminada afecta las especies de fauna y flora. Se calcula que $1 / 4$ parte de las enfermedades provienen de esta fuente. Por lo tanto,

[...] dos factores han caracterizado la irrupción de la problemática ambiental en el discurso social y político actual; el deterioro objetivo y creciente del medio ambiente y la extensión de la conciencia social de dicha degradación y los procesos que origina para la existencia misma del hombre [23].

Como otros juristas, entendemos que el Derecho Ambiental, cobra vida a partir de la Conferencia Mundial sobre Medio Humano llevado a cabo en Estocolmo (1972), a partir de allí la comunidad internacional y en particular los que tenemos la difícil tarea de legislar, comenzamos apreciar que la eficacia de la norma jurídica que aborde la problemática ambiental está determinada fundamentalmente, por la capacidad que tenga la misma de abordar con carácter sintético cada recurso o componente que pretenda conservar. Ser eficaz depende,

"[...] de una adecuada percepción del ambiente, esto es, de que opere sobre la base de que el ambiente constituye un acoplamiento organizado de subsistemas ecológicos funcionalmente interdependientes, constituidos, a su turno, por factores dinámicamente interrelacionados.[24]

Veinte años después de Estocolmo y cumpliendo un mandato de la Conferencia se reúnen en Río de Janeiro el 4 de junio de 1992 la "Conferencia de NNUU sobre el Medio Ambiente y el Desarrollo". Cumbre que dio lugar a una serie de instrumentos jurídicos de carácter internacional como son:

- La Declaración de Río sobre Medio Ambiente y Desarrollo. Programa 21 Establecimiento de un marco jurídico y Reglamento Eficaz. Convención sobre la Diversidad Biológica. Convenio Marco de la NNUU sobre Cambio Climático.- Declaración de Principio sobre los Bosques de todo tipo.

- La Declaración de Río con sus 27 principios retoma conceptos y posiciones ya enunciados tanto en Estocolmo como en el Informe Nuestro Futuro Común.

El principio número uno, reconoce el papel protagónico del hombre en el desarrollo sostenible, no puede ser de otra forma. El desarrollo sostenible es una categoría creada por el hombre para regular el alcance de su derecho al uso y disfrute de los recursos naturales, partiendo que es la única especie que interactúa con el resto de la diversidad biológica, no sólo para sobrevivir sino para desarrollarse individual y colectivamente de forma consciente y no movido por instintos primarios. El principio tres, define el marco 
de este derecho de forma tal que responda equitativamente a las necesidades de desarrollo y ambientales de las generaciones presentes y futuras. Se introduce el elemento necesidades ambientales no contenidos en el Informe Brundtland y principio nueve, hace un llamado a la solidaridad para el logro del desarrollo sostenible. Entendemos que este lugar primado que ocupa el concepto de Sostenibilidad es un reconocimiento al papel y la responsabilidad que tiene el hombre en la conservación del medio ambiente. $Y$ aquí se imbrican dos elementos que a los efectos del tema que estamos tratando, queremos destacar de la Cumbre de Río.

La Conservación de la Vida, no es ninguna acción romántica o de compasión por una especie cualquiera que se encuentra en peligro de extinción. La Conservación es algo sumamente superior. Es reconocer que cada especie, tiene un valor intrínseco superior a cualquier valoración o estimación humana. Cada organismo tiene una dignidad y un derecho a la vida que ningún ser humano puede regatearle y mucho menos arrebatarle [25]

Al analizar la Convención sobre Diversidad Biológica, vemos como uno de los planteamientos más significativos, el reconocimiento que hace en su preámbulo al valor intrínseco de la diversidad biológica. Este pronunciamiento si bien va dirigido al componente "Vida" de lo que entendemos como medio ambiente, extiende su imperio al mismo como un todo, partiendo de que la diversidad biológica se sustenta, en un constante flujo y reflujo con otras formas de existencia de la materia y el espacio que la rodea. Es justo señalar que con anterioridad, el Informe Brundtland, había hecho igual pronunciamiento al expresar;

El material genético de las especies silvestres reporta miles de millones de dólares anuales a la economía mundial, en forma de especies mejoradas en vegetales comestibles, nuevos fármacos, medicamentos y materia prima para la industria. Pero aun prescindiendo de la utilidad, hay motivos de orden moral, éticos, culturales, estéticos y puramente científicos para conservar las especies silvestres". La existencia [...] de los organismos y especies vegetales y animales que pueblan la tierra, surgieron como resultado de un proceso largo y complejo en que la contingencia desempeño un papel capital [26].

Esta singularidad en su surgimiento, que trasciende al hecho mismo, de que todavía hoy la ciencia no logra una definición exacta de su esencia acentúa nuestro deber, como un componente más que somos del todo del que habló Holbach, o de lo general a que se refería Lenin, a adecuar nuestra acción como criaturas conscientes, al respeto y conservación del medio ambiente, depositario de este tesoro que es la vida. Aquí retomamos a Holbach 
[...] el hombre no tiene ningún motivo para creerse un ser privilegiado por la naturaleza puesto que está sujeto a las mismas vicisitudes que sus demás producciones, [...] Así como el árbol produce los frutos peculiares de su especie, así el hombre según su energía particular produce sus frutos, que son sus acciones y sus obras igualmente necesarias, se convencería de que en la ilusión que le da tan buena idea del mismo, proviene de que es al mismo tiempo espectador y porción del universo y, al final llegará a conocer que la idea de la excelencia de su ser no tiene un fundamento que el de su propio interés y la producción natural que guarda para consigo mismo. [27]

Evolución de actuaciones ambientales a nivel mundial: [28]

\begin{tabular}{|l|l|l|}
\hline 1972 & $\begin{array}{l}\text { Primerinforme } \\
\text { al Club de } \\
\text { Roma }\end{array}$ & $\begin{array}{l}\text { Este informe también se denominó los limites del } \\
\text { crecimiento, el cual reconoce por vez primera que no } \\
\text { puede haber crecimiento económico ilimitado con } \\
\text { recursos limitados. } \\
\text { Se debia actuar de inmediato con el objetivo de frenar el } \\
\text { crecimiento demográfico, limitar el consumo de } \\
\text { alimentos y materias primas y reducir la contaminacion y } \\
\text { la producción industrial. }\end{array}$ \\
\hline 1972 & $\begin{array}{l}\text { Conferencia de } \\
\text { Estocolmo }\end{array}$ & $\begin{array}{l}\text { Primera conferencia de la ONU sobre medio ambiente a } \\
\text { escala mundial, estuvieron 113 naciones, se crea el } \\
\text { PNUMA, que diez años más tarde se denominaria } \\
\text { estrategia mundial de conservación de la naturaleza. }\end{array}$ \\
\hline 1987 & $\begin{array}{l}\text { Informe } \\
\text { Brundtland }\end{array}$ & $\begin{array}{l}\text { Este concepto de desarrollo sostenible se acuña en este } \\
\text { informe, publicado con el nombre de Nuestro futuro } \\
\text { común, realizado por encargo de la ONU. }\end{array}$ \\
\hline 1987 & $\begin{array}{l}\text { Protocolo de } \\
\text { Montreal }\end{array}$ & $\begin{array}{l}\text { Se asentaron las bases para la progresiva reducción de } \\
\text { las sustancias contaminantes que aun hoy agotan la } \\
\text { capa de ozono. Las metas para reducir los gases CFC, } \\
\text { halones y bromuro de metilo. }\end{array}$ \\
\hline
\end{tabular}

\begin{tabular}{|c|c|c|}
\hline 1992 & $\begin{array}{l}\text { Cumbre de la } \\
\text { Tierra o } \\
\text { conferencia de } \\
\text { Río }\end{array}$ & $\begin{array}{l}\text { Su objetivo principal, fue reafirmar la declaración de la } \\
\text { ONU (Estocolmo de 1972) y adoptar un enfoque de } \\
\text { desarrollo que protegiera el medio ambiente, mientras se } \\
\text { aseguraba el desarrollo económico y social; de la misma } \\
\text { surgieron cinco documentos, suscritos por los países } \\
\text { participantes: } \\
\text { - Declaración de Rio, sobre medio ambiente y } \\
\text { desarrollo, se definen derechos y deberes de los } \\
\text { Estados. } \\
\text { - Convenio sobre la diversidad biológica. } \\
\text { - Declaración de principios sobre el manejo, la } \\
\text { conservación y el desarrollo sustentable de los } \\
\text { bosques. } \\
\text { - Convenio marco sobre el cambio Climatico. } \\
\text { menda } 21 \text { o programa } 21 \text {, su finalidad definir las } \\
\text { Se crearon comites y organizaciones como: } \\
\text { - El convenio marco de la ONU sobre el cambio } \\
\text { climático. } \\
\text { Comisión de las Naciones Unidas para el } \\
\text { desarrollo sostenible. }\end{array}$ \\
\hline
\end{tabular}




\begin{tabular}{|c|l|l|}
\hline 1996 & $\begin{array}{l}\text { Conferencia } \\
\text { Hábitat II }\end{array}$ & $\begin{array}{l}\text { Se ejecuta en Estambul, Turquia; sirvió para determinar } \\
\text { las bases del programa Hábitat, el cual está vigente } \\
\text { actualmente, caracterizado por un modelo de ciudad } \\
\text { encaminado a mejorar las condiciones de vida del } \\
\text { hombre, desde la politica del desarrollo sostenible y la } \\
\text { problemática de la humanidad. }\end{array}$ \\
\hline 1997 & $\begin{array}{l}\text { Segunda } \\
\text { Cumbre de la } \\
\text { Tierra }\end{array}$ & $\begin{array}{l}\text { Se celebra en Nueva York, con el objetivo de revisar y } \\
\text { determinar los objetivos del estado de compromiso que } \\
\text { habia sido asumido en la anterior cumbre de la tierra de } \\
\text { Rio de Janeiro. } \\
\text { Se define un plan de trabajo al constarse lo lejos que } \\
\text { aun se estaba de este cumplimiento, definiendo un plan } \\
\text { de trabajo para los próximos cinco años (1997-2002), } \\
\text { definiendo las estrategias nacionales por cada país para } \\
\text { un desarrollo sostenible. }\end{array}$ \\
\hline 1997 & $\begin{array}{l}\text { Conferencia de } \\
\text { Kyoto }\end{array}$ & $\begin{array}{l}\text { Este se realiza en Kyoto -Japón- se intentó llegar a un } \\
\text { acuerdo para la protección de clima, definidos en la } \\
\text { cumbre de la tierra de 1992. Se pudo comprobar que } \\
\text { estábamos muy lejos del cumplimiento de éstos. Su } \\
\text { mayor logro fue la elaboración, firma y ratificación de } \\
\text { unamayoría de los países firmantes (de los no firmantes } \\
\text { se destaca los EUA). Documento que recoge medidas } \\
\text { para la progresiva reducción de los gases de efecto } \\
\text { invernadero. }\end{array}$ \\
\hline
\end{tabular}

\begin{tabular}{|c|c|c|}
\hline 1998 & $\begin{array}{l}\text { Protocolo de la } \\
\text { protección de } \\
\text { la Antártida }\end{array}$ & $\begin{array}{l}\text { Se reconoce a la Antártida el interés para toda la } \\
\text { humanidad, pues desde } 1959 \text { se habia firmado el } \\
\text { Tratado Antártico, aceptado por } 45 \text { países. Fue } \\
\text { acordado: } \\
\text { - Se utilizará sólo para fines pacíficos. } \\
\text { - Promover la cooperación internacional para la } \\
\text { investigación científica. } \\
\text { - No se harán nuevas reclamaciones sobre } \\
\text { soberania territorial en la Antártida. } \\
\text { - Se prohíbe la eliminación de desechos } \\
\text { radioactivos y explosiones nucleares. } \\
\text { Finalmente producto de los fuertes movimientos } \\
\text { ecologistas mundiales, este tratado se completó } \\
\text { recogiéndose en el Protocolo al Tratado de la Antártida } \\
\text { sobre la protección al medio ambiente o protocolo de } \\
\text { Madrid. }\end{array}$ \\
\hline 1998 & $\begin{array}{l}\text { Conferencia } \\
\text { de Buenos } \\
\text { Aires }\end{array}$ & $\begin{array}{l}\text { Su objetivo fue superar los problemas que habian } \\
\text { surgido en la cumbre anterior (Kyoto) y revisar estos } \\
\text { objetivos. }\end{array}$ \\
\hline
\end{tabular}




\begin{tabular}{|c|c|c|}
\hline 2001 & $\begin{array}{l}\text { Acuerdo de } \\
\text { Bonn }\end{array}$ & $\begin{array}{l}\text { El protocolo de Kyoto establece tres mecanismos de } \\
\text { flexibilidad, para facilitar a los paises del anexo } 1 \text { de esta } \\
\text { convención ( paises desarrollados y con economias de } \\
\text { transición de mercado) la consecución de sus objetivos } \\
\text { de reducción y limitación de emisiones de gases de } \\
\text { efecto invernadero: } \\
\text { - Comercio de emisiones. } \\
\text { - Mecanismo de desarrollo limpio. } \\
\text { - Mecanismo de aplicación conjunta. } \\
\text { pon este acuerdo se busco además estipular los } \\
\text { principios y las líneas generales en la utilización de los } \\
\text { mecanismos de flexibilidad. }\end{array}$ \\
\hline 2001 & $\begin{array}{l}\text { Acuerdo } \\
\text { de Marrakech }\end{array}$ & $\begin{array}{l}\text { Los principios rectores de los mecanismos de flexibilidad } \\
\text { se definieron en el acuerdo de Bonn de 2001, y se } \\
\text { recogen en los textos legales de Marrakech }\end{array}$ \\
\hline 2002 & $\begin{array}{l}\text { Cumbre } \\
\text { de } \\
\text { Johannesburgo }\end{array}$ & $\begin{array}{l}\text { Cumbre mundial sobre el desarrollo sostenible, su } \\
\text { principal objetivo fueron la adopción de compromisos } \\
\text { concretos con relación a la agenda } 21 \text {, así como el logro } \\
\text { del desarrollo sostenible }\end{array}$ \\
\hline
\end{tabular}

\begin{tabular}{|c|l|l|}
\hline 2004 & $\begin{array}{l}\text { Décima } \\
\text { conferencia } \\
\text { de París }\end{array}$ & $\begin{array}{l}\text { Se celebra en Buenos Aires, Argentina. Tiene como } \\
\text { objetivo evaluar lo alcanzado hasta ese momento en la } \\
\text { Convención y los desafios futuros teniendo en cuenta la } \\
\text { entrada en vigor del protocolo de Kyoto el 16 de febrero } \\
\text { de 2005. }\end{array}$ \\
\hline 2005 & $\begin{array}{l}\text { Cumbre } \\
\text { Mundial }\end{array}$ & $\begin{array}{l}\text { Compromisos y obligaciones de los países en un } \\
\text { convenio marco de la ONU sobre el Cambio Climático y } \\
\text { el protocolo de Kyoto, para tratar los números desafíos } \\
\text { encarados para combatir el cambio climático, promover } \\
\text { energias limpias, resolver las necesidades energéticas y } \\
\text { lograr el desarrollo sostenible. }\end{array}$ \\
\hline 2005 & $\begin{array}{l}\text { Undécima } \\
\text { conferencia } \\
\text { de París }\end{array}$ & $\begin{array}{l}\text { Entre los acuerdos firmados, los más destacados son: } \\
\text { Aprobar los acuerdos de Marrakech } \\
\text { - Comenzar el proceso de negociación para el } \\
\text { período posterior a 2012, 2do compromiso de } \\
\text { compromisos del protocolo de Kyoto. }\end{array}$ \\
\hline
\end{tabular}

El tema como continuidad de artículos escritos por el autor principal y ahora en coautoría en relación con la temática medioambiental, es el resultado de mis experiencias cuando ejercité la función de auditor gubernamental y ahora en el ejercicio de la docencia, tiene como objetivo demostrar la pertinencia de la solución de los conflictos medioambientales como resultado de la responsabilidad ambiental en relación con la protección del medioambiente y en particular, la relacionada con la protección de los animales, hacemos una revisión histórica en relación con la institución jurídica, la base legal que la sustenta en diversas etapas que han sido objeto de análisis, los organismos implicados, haciendo una mirada a la legislación medioambiental y otra a los órganos de control con competencia y jurisdicción, como al resto de los organismos de la Administración Pública que tributan con su legislación a acciones dirigidas a la protección medioambiental. El problema científico de la investigación radica en la inacción en la solución de los conflictos en materia medioambiental. Nos permitirá continuar nuestra labor de investigación en relación con el tema, al abordar en investigaciones posteriores, o si se hará cumplir lo que dispone por la Ley del Medio Ambiente y su trascendencia a la vía 
jurisdiccional. Como métodos de investigación utilizamos la revisión bibliográfica, tanto de normativas jurídicas nacionales y en torno al derecho comparado, las entrevistas con expertos que ejercitan la auditoría y la inspección ambiental indistintamente en el CITMA, Organismos de la Administración Central del Estado y en la Contraloría General de la República, los criterios de juristas vinculados a la labor medioambiental, juristas en su labor profesional como fiscales y jueces; se hizo uso del método heurístico, el axiológico, que permitió formar un criterio respecto a la institución jurídica analizada, en una dimensión social-jurídica valorativa, que en plano económico nos permitió conocer las aristas del problema científico tratado. Las consecuencias en relación con los actores dentro del contexto social, las acciones relacionadas con la modificación del entorno, que tributan a incrementar la cultura jurídica en materia medioambiental, incidiendo de esta forma en las decisiones políticas por parte del Estado y su estrecha relación con la toma de decisiones en el orden económico puedan incidir, en torno a la cultura del impacto.

\section{CONSIDERACIONES ACERCA DE LA HISTORIA AMBIENTAL}

La historia ambiental, como término de uso reciente compartido en ocasiones con los de historia, ecología y eco historia, no constituye una perspectiva interesante nueva de mirar al pasado. Desde siempre, el ser humano se ha preocupado por su relación con el medio natural. [29] Es posible decir, sin embargo que la forma en que comienza a verse esta relación en el tiempo por parte de la historia ambiental sí representa un cambio de perspectiva. En lugar de dirigirse de manera predominante a destacar las determinaciones que el medio físico ha imputado a la sociedad, aparece ahora en un lugar preponderante la indagación sobre cómo la cultura material y espiritual del ser humano ha moldeado y modificado su entorno natural y cuáles son sus consecuencias. La historia ambiental se ocupa de las interacciones mutuas del ser humano con el resto de la naturaleza, tal y como expresó un destacado historiador ambiental norteamericano John R. McNeillv [30], o como indican dos autores primero de España, se trata de "entender la historia como un proceso de evolución entre los humanos y su medio partiendo del carácter inseparable de los sistemas sociales y ecológicos". [31] Se considera que el nacimiento formal de la historia ambiental se produjo en círculos académicos norteamericanos y europeos como reacción de los estudios del pasado a la profunda crisis medioambiental de la sociedad contemporánea. No quiere decir que sea este un movimiento exclusivo de historiadores, por el contrario, tiene como novedad el incorporar especialistas de diversas disciplinas bajo el fin común de estudiar los orígenes y antecedentes de muchas de las problemáticas actuales en la relación de los seres humanos con el resto de la naturaleza. La historia ambiental representa un esfuerzo por conectar los resultados de diferentes disciplinas de las ciencias naturales y las ciencias sociales, que no deja de tener el ser humano como protagonista principal, pero que a la vez lo 
inserte en una red de interacciones sociales, económicas, políticas, biológicas, geofísicas y ecológicas. [32] A lo largo de los últimos veinte años, la persistente combinación de crecimiento económico mediocre e incierto, el deterioro social y la degradación ambiental que aquejan a la América Latina, han estimulado un creciente interés por las formas de interacción entre nuestras sociedades y su medio natural, a lo largo del tiempo, y por las consecuencias que se han derivado de esa interacción para ambas partes. Así ha empezado a tomar forma en nuestra cultura una historia ambiental que, si por un lado se nutre de los desarrollos de tal disciplina en su mundo noratlántico de origen, por el otro va adquiriendo perfil y tareas propias en su propio mundo. El punto de origen de este proceso puede ser ubicado a fines de la década de los 70's, cuando empezó a manifestarse un creciente interés en los problemas ambientales de la región por parte de organismos internacionales y de algunas instituciones académicas. Y en 1978 el geógrafo Chileno Pedro Cunill [33] señaló la necesidad de establecer un horizonte histórico para el análisis de los problemas ambientales, y en 1980 Nicolo Gligo [34] y Jorge Morillo [35] publicaron un artículo "Notas sobre la historia ecológica de América Latina", que sintetizaba el estado de la discusión sobre el tema en el marco de la teoría del desarrollo. Tres años después el sociólogo chileno Luis Vitale [36] publicó un ensayo concedido, en lo fundamental, como una réplica de izquierda al planteamiento del tema desde la Comisión Económica para América Latina [37], que enfatizaba las limitaciones de la teoría del desarrollo para dar cuenta de los costos ambientales del crecimiento económico en la Región.

Ese primer momento de conformación, no obstante, desembocó en un interregno que se prolonga hasta principio de la década de 1990, cuando las perspectivas de la Conferencia Mundial sobre Medio Ambiente y Desarrollo [38], celebrada en Río de Janeiro en 1992 proporcionaron una renovación del interés por el tema en la región. Por contraste, a partir de aquí se inicia un momento nuevo en la evolución de esta historia, en el que las preocupaciones por la llamada "variable ambiental" del desarrollo van cediendo lugar a la reflexión sobre las consecuencias ambientales de lo que había venido acaeciendo realmente en la región.[39] Para la segunda mitad de la década, este segundo momento había desembocado en una fase nueva de madurez, marcado por aportes como los del colombiano Alberto Flores Malagon y nuevos textos del chileno Pedro Cunill [40] Lo fundamental, sin embargo, es que la historia ambiental ya forma parte de la cultura latinoamericanaespecialmente en Cuba, desde donde nos ayuda a comprender de qué manera nuestros problemas ambientales de hoy son la consecuencia de las formas en que han venido siendo organizados nuestras relaciones en el mundo natural a lo largo de los últimos cinco siglos y, en particular, de los últimos cincuenta años. Empezamos a entender así, que cuando se estudia "un acto histórico, o un acto individual", se ve que la intervención humana en la naturaleza acelera, cambia o detiene la obra de éste, y que 
toda la historia es solamente la narración del trabajo de ajuste, y los combates entre naturaleza extrahumana y la naturaleza humana. Cuba al igual que toda nuestra América se suma en voz propia a la creación de la cultura nueva que, desde todos los rincones del planeta, reclama un desarrollo sostenible por humano que sea y se comprenda una vez más, que sólo seremos universales en la medida que seamos auténticos.

\section{LA INACCIÓN EN LOS CONFLICTOS AMBIENTALES EN TORNO A LA JUSTICIA AMBIENTAL, PANORAMA CUBANO}

La Constitución de la República de Cuba [41] en su artículo 27 dice que:

El estado protege el medio ambiente y los recursos naturales del país, reconoce su estrecha vinculación con el desarrollo económico y social sostenible para hacer más racional la vida humana y asegurar la supervivencia, el bienestar y la seguridad de las generaciones actuales y futuras. Corresponde a los órganos competentes aplicar esta política.

Es deber de la ciudadanía contribuir a la protección del agua, la atmósfera, la conservación del suelo, la flora, la fauna y todo el rico potencial de la naturaleza. Consecuentemente en la práctica trazada por el Partido y el precepto constitucional citado; la Asamblea Nacional del Poder Popular aprobó la Ley número 33 del 10 de enero de 1981 "de protección del medio ambiente y el uso racional de recursos naturales" [42], en la que se establecen los principios básicos para la conservación, protección, y mejoramiento del medio ambiente y el uso racional de los recursos naturales conforme con la política integral del país, la Disposición Especial Segunda de esta Ley dispuso que los conflictos de carácter económico que se susciten sobre esta materia los conozca y decida el Órgano de Arbitraje Estatal competente [43] y por el Decreto número 119 del 29 de septiembre de 1983 que establece "las reglas para determinar la competencia de los órganos de Arbitraje Estatal" facultó dichos Órganos y a los adscritos a los organismos de la Administración Central del Estado para conocer y decidir los conflictos ambientales; definiendo que el objeto de la jurisdicción son los conflictos ambientales. La regla Segunda del citado Decreto número 119, al pretender definir el concepto de conflicto ambiental determina su alcance, al expresar que son aquellas cuestiones de carácter económico, contractuales y extracontractuales que se originen en materia de Protección del Medio Ambiente o uso racional de los recursos naturales, por lo que esta regla no se circunscribe estrechamente a las relaciones interempresariales, sino al ámbito económico en general, lo que implica que el arbitraje estatal pudo entrar a conocer cualquier actividad infractora de la protección del medio ambiente o uso irracional de los recursos naturales que tuviera connotación económica, aún en el caso de no poder precisar la agresión, ni 
poder cuantificar exactamente los daños. En cuanto a las medidas a imponer, el artículo 127 de la Ley número 33 Establece:

Las acciones $u$ omisiones no constitutivas de delito que infrinjan lo preceptuado en la presente Ley u otras disposiciones legales referidas a la protección del medio ambiente y el uso racional de los recursos naturales, son sancionadas con multas administrativas $y$, en su caso, con medidas de retención, sacrificio, destrucción, decomiso, reembarques, prohibición de descargar, reparación de los daños u otras.

La autoridad administrativa competente en cada caso ordena el cese de la actividad infractora, así como cuando proceda, dicta las medidas necesarias para la restauración, subsanación o rehabilitación de los objetos del medio ambiente o de los recursos naturales dañados, contaminados o perjudicados. Con todo, el artículo 130 limita estas facultades, y las condicionó a una legislación futura.

El Consejo de Ministros reguló los procedimientos o normas para la protección del medio ambiente y el uso racional de los recursos naturales y define las autoridades administrativas facultadas para ello dentro del Sistema de la Administración del Estado. También reguló el procedimiento para disponer las medidas de rehabilitación o subsanación de la contaminación, daños o perjuicios causados, cuando procediera.[44]

Analizando que la Ley 33 reguló la competencia del Arbitraje Estatal para los conflictos en esta materia, el Decreto No. 23 [45] señaló los objetivos del Sistema de Arbitraje Estatal y que éstos fueron órganos especiales de la Administración Central del Estado con funciones de dirección estatal, así como se definió desde el Primer Congreso del Partido Comunista de Cuba la política para la protección y mejoramiento del medio ambiente como el aprovechamiento racional de los recursos naturales y en el Informe Central al Tercer Congreso del Partido Comunista de Cuba [46]; Fidel analizó que, aunque se ha elevado la conciencia en este sentido el avance en la lucha contra la contaminación ha sido lento y sólo se aprovechan los residuales en un reducido número de instalaciones, los sistemas de tratamiento son deficientes o no funcionan, de los que se colige la posibilidad del Arbitraje de actuar activamente pues si un Órgano de Arbitraje Estatal le dicta un plan de medidas a una empresa para que restaure, subsane o rehabilite el medio que afectó, actuaba consecuentemente, no sólo con el espíritu de la Ley, sino al fortalecimiento de la política del Partido; también fue consecuente si dispuso el cese o la interrupción de una actividad infractora que afecte o pueda afectar la economía del país y cuando decide, la reanudación de la actividad una vez eliminada su infracción. Es importante destacar que dentro de las decisiones de la actual política del proyecto social cubano, los lineamientos [47] acordados en el sexto congreso del Partido Comunista de Cuba, en el año 2011 y 2012 [48], donde hay 
disposiciones relacionadas con el tema medio ambiental, que permitirá a la Administración Pública dirigir acciones encaminadas a potenciar la cultura del impacto ambiental, con acciones dirigidas a proteger el medio ambiente por los actores involucrados. El Arbitraje Estatal en este momento histórico conoció de oficio, casos de contaminación ambiental a partir de lo siguiente:

Que la contaminación afecte cualquier objetivo económico que el Estado debe tutelar. Que la contaminación se produzca por el uso irracional de los recursos económicos mediante vertimiento o expulsión a la atmósfera de materia primas secundarias, consideradas erróneamente como desechos residuales. Ejemplos: el mosto de los centrales azucareros o los gases sulfurados que expulsan a la atmósfera las industrias que queman petróleo, partiendo de la concepción científica de que no existen residuales industriales inútiles. Que no es necesario que esté precisado o se pueda precisar el damnificado, ni se pueda cuantificar los daños, si es evidente la afectación económica. La contaminación al río Bayamo de los desechos líquidos de las industrias, instalaciones hospitalarias, desagües de albañales domésticos, etc.

En los ejemplos expuestos no siempre es medible la afectación económica y sin embargo, es evidente que existió. Los Órganos de Arbitraje Estatal Territorial [49] pudieron conocer de los focos de contaminación ambiental que afectan cualquier objetivo económico, dictar planes de medidas que se atemperen a los planes de inversiones que sobre medio ambiente tengan las empresas, o las medidas recomendadas por la Comisión Provincial del medio ambiente. En todos los casos el Arbitraje pudo exigir y controlar, autoritariamente, el cumplimiento de los referidos planes de inversiones o las medidas recomendadas por la citada Comisión Provincial. La interpretación de esta legislación le dio al Sistema de Arbitraje Estatal la posibilidad de pasar a una posición ofensiva en lo concerniente a los "conflictos ambientales".

La solución de los conflictos ambientales, a la luz de la jurisdicción económica y civil. En principio la Ley número 81 sobre el Medio Ambiente [50], no excluye jurisdicción alguna en clara alusión a las diversas responsabilidades que pueden suscitarse; la penal, administrativa contenciosa, civil o económica. La tutela de esos derechos por vía jurisdiccional con preeminencia como se conoce dado el tratamiento penal de nuestro Código que sólo recoge hechos donde se manifiestan conductas que traen impacto negativo en el medio ambiente; pero no está presente el Delito Ecológico ni existe organización de un título especial de esa regulación y que su alcance en la norma y la finalidad están muy lejos de la principal tarea de prevención; como tampoco se conoce en las perspectivas de modificaciones inserción alguna de figuras típicas medio ambientales en el Derecho Penal. [51] Por lo que al desaparecer y extinguirse el Sistema de Arbitraje Estatal y crearse la Sala de lo Económico en los Tribunales Populares, mediante el Decreto Ley número 129 del año 1991[52], dichas salas de Justicia 
continuaron aplicando como reglas las de Procedimiento previstas en el Decreto número 89 del 1981, hasta tanto surgieran las futuras modificaciones, con las adecuaciones de la Instrucción número 141 de fecha 27 de septiembre de 1991 [53] del Consejo de Gobierno del Tribunal Supremo Popular. Los conflictos del medio ambiente en la mayoría de los casos se han conocido en las Salas de lo Económico, ratificando el conocimiento de los mismos al Decreto número 223 del 15 de Agosto del 2001 [54], por lo que uno de los puntos controvertidos para determinar la jurisdicción y competencia entre lo Civil y lo Económico, sobre este particular fue el Dictamen número 350 [55] del Consejo de Gobierno. Sí una u otra jurisdicción era competente para conocer los daños permanentes o eventuales al medio ambiente, el citado Dictamen se manifiesta planteando el principio de unidad de competencia, por lo que cualquier reclamación por conflictos de esa razón será de conocimiento de las Salas de lo Económico. Es criterio que para determinar una u otra jurisdicción se deberá atender a los sujetos que intervienen en el daño acontecido por el impacto negativo medio ambiental y si la causa se origina por la actividad comercial o productiva de los sujetos que intervienen; pero en la práctica forense son casi inexistentes los reclamos por la vía jurisdiccional de lo Civil.

Al promulgarse el Decreto-Ley número 241 [56], modificativo de la Ley de Procedimiento Civil, Administrativo y Laboral de 26 de Septiembre del 2006, fue ratificado la competencia de la jurisdicción de las Salas de lo Económico de los Tribunales Populares, cuando expresa que corresponde a estas Salas el conocimiento y solución de los litigios o conflictos que surjan con motivo del incumplimiento de las regulaciones sobre la protección al medio ambiente y los recursos naturales, o relacionados con daños ambientales, resultantes de actividades económicas desarrolladas por personas jurídicas o naturales cubanas 0 extranjeras, en el territorio nacional, comprendidas las aguas interiores, el mar territorial, la zona económica exclusiva y la plataforma continental; de lo que se colige que cuando existe alguna afectación ambiental entre las familias naturales, es del conocimiento de la jurisdicción civil en un proceso que se caracteriza por las relaciones de vecindad. Indudablemente los jueces deben conocer en principio los instrumentos legales para enfrentar los hechos discurridos a la norma en dichos conflictos; sin lugar a dudas de primera importancia debe recurrirse a la Constitución de la República en el conocido artículo 27 que recoge las modificativas de ese texto en el año de 1992 atemperado a los nuevos conceptos de la Cumbre de Río sobre el medio ambiente, el desarrollo sostenible y sustentable. [57] En el derecho sustantivo tiene una significativa aplicación el Código Civil Cubano, Ley número 59 de 1987 [58], pues es conocido que la mayoría de los asuntos se refieren a la responsabilidad por actos ilícitos que se enmarcan en la responsabilidad civil objetiva conocida como responsabilidad aquiliana o extracontractual ver los artículos 81, $82,83,84,85$ inciso (f) , y 86 los que se relacionan con otros de 
ese propio texto como el artículo 95 y siguiente, la prescripción y caducidad de los derechos que en reclamaciones de la naturaleza apuntada se remite a la Instrucción número 161 de fecha 19 de septiembre del 2000 [59] del Consejo de Gobierno del Tribunal Supremo Popular se establece que el derecho para tales acciones caduca al año y lo relaciona con la prescripción de la acción del inciso d) del artículo 116 del texto legal precitado.

Sin lugar a dudas se utiliza como norma fundamental la Ley número 81 sobre el medio ambiente [60], cuya preceptiva general permite situar al operador del derecho, los principios, conceptos básicos y objetivos, los instrumentos de la política y la gestión ambiental, planificación, el ordenamiento ambiental, la licencia ambiental, responsabilidad en que se incurre por daño medio ambiental, entre otras y los recursos naturales objeto de protección, por ser un Derecho Horizontal que deviene en una relación directa con otros cuerpos legales normativos que según el conflicto se deben utilizar, ejemplo: la Ley número 76 , Ley de Minas [61]; la Ley número 85, Ley Forestal [62]; el Decreto-Ley número 138 [63], sobre la aguas terrestres; los tratados y acuerdos de esta materia donde Cuba es parte de obligatorio cumplimiento al ser ratificados por la Asamblea Nacional. Actualmente el conocimiento de las Salas de lo Económico de los Tribunales Populares en materia económica se espera alcance un importante avance al conocerse las modificaciones de la Ley de Procedimiento Civil, Administrativo, Laboral y Económico, con el Decreto-Ley número 241 antes referido, en cuyo tenor se pronuncia en materia medioambiental, en aras de alcanzar el principio de unidad de jurisdicción, que dichas Salas conozcan las demandas que pueden establecer los ciudadanos contra las Entidades Infractoras, a la que posibilita el ejercicio de acciones resarcitorias como de cumplimento, para prevenir el daño ambiental, las que igualmente pudieran ser ejercidas por el Ministerio de Ciencia Tecnología y Medio Ambiente [64] o por la Fiscalía General de la República y el Ministerio de la Agricultura en materia de Patrimonio Forestal que refleja que las sentencias dictadas en procesos medio-ambientales referidas al daño, no causa estado de cosa juzgada, quedando legitimado el perjudicado para ejercitar nuevas acciones reclamatorias por la continuidad de los efectos del evento daños que haya dado lugar a la misma. En virtud de la Ley número 81 del 11 de julio de 1997 "De Medio Ambiente", se encomienda a las Salas de lo Económico de los Tribunales Populares, la solución de los conflictos originados por la aplicación de lo que en la misma se dispone, conforme se establezca por el Consejo de Gobierno del Tribunal Supremo Popular sin perjuicio de que sean conocidos y resueltos en sus propias jurisdicciones las materias civiles, penales, contenciosasadministrativo y administrativos-contravencionales que correspondan.[65] Al promulgarse por el Consejo de Estado el día 15 de agosto del 2001, el Decreto Ley número 223 "De la Jurisdicción y Competencia de las Salas de lo Económico de los Tribunales Populares", en su disposición segunda del Artículo 1, 
estableció que serán del conocimiento de la Sala de lo Económico, las demandas que promuevan contra las personas naturales 0 jurídicas descrita en el apartado primero, es decir, todas las entidades estatales, las sociedades mercantiles y demás entidades privadas, instituciones financieras y organizaciones sociales y de masas, asociaciones y fundaciones, cooperativas, unidades básicas de producción, pequeños agricultores y otras poseedores de tierras, con motivo del incumplimiento de las regulaciones sobre la protección al medio ambiente y el uso racional de los recursos naturales en el desarrollo de sus actividades productivas o de comercio, ya sean promovidas las mismas por algunas de estas personas o por la Fiscalía General de la República o el Ministerio de Ciencia, Tecnología y Medio Ambiente, de conformidad con la legislación vigente. En tal sentido es donde podemos abordar el tema de la inacción de los organismos competentes en la solución de los conflictos medioambientales desde esa fecha, por cuanto en todo el período de vigencia del Decreto 223 de la "Jurisdicción y Competencia de las Salas de lo Económico" [66], no han presentado demanda ante la Sala ni el Ministerio de Ciencia, Tecnología y Medio Ambiente ni la Fiscalía General de la República, [67] a pesar de conocerse de muchas infracciones de las regulaciones de la Ley número 81 y de otras Leyes que complementan el sistema y que vienen afectando la economía del País y en otros casos, afectan la salud ambiental; conociéndose que por estos organismos se dictan medidas, se imponen multas o se realizan dictámenes para su solución administrativa la que no en todos los casos son materializadas por la necesidad de la proyección de inversiones para la solución del problema planteado, lo que implica la continuidad de la afectación al medio ambiente y a los recursos naturales. El actual órgano de control y fiscalización, la Contraloría de la República [68] y el posterior acuerdo del Consejo de Estado que reglamenta su actuar, le abrogan la función constitucional como órgano supremo del Estado cubano, en materia de fiscalización y control, sobre los órganos del Estado y del gobierno, con subordinación jerárquica al Consejo de Estado, amparados en el artículo 75 de la Constitución cubana, actuar en materia ambiental, a través del ejercicio de la auditoría ambiental o ecológica, la que aún no se ejercita. [69]

La solución de los conflictos medioambientales en la sala de lo económico del Tribunal Provincial Popular en Granma. En la provincia Granma la Delegación del Ministerio de Ciencia, Tecnología y Medio Ambiente desde el año 2002 al 2005, sancionó a sesenta entidades e impuso como medida en la obligación de hacer a cuarenta y un casos y como clausura temporal a tres entidades; asimismo impuso veintinueve multas institucionales y una multa personal, lo que demuestra también una inacción en cuanto al procedimiento administrativo contravencional como parte del derecho administrativo sancionador [68], si se tiene en cuenta el nivel de violaciones que en este sentido medioambiental se conoce. Las principales violaciones en este período están dadas en el incumplimiento de las inspecciones ambientales estatales 
reguladas por la Resolución número 130 de 1995 [70]; el vertimiento de residuales líquidos a la zona costera; el inicio obras sin licencias ambientales y la inadecuada disposición de desechos peligrosos, lo que es de colegir que independientemente a la multa o medida impuesta, debieron haber promovido la demanda judicial a los efectos de obligar a la eliminación del efecto dañoso, a la paralización de la obra o a la indemnización de los perjuicios económicos ocasionados, pues muchos de tales incumplimientos de medidas tuvieron o tienen un impacto negativo sobre el medio ambiente y por consiguiente económico sobre otras entidades que utilizan el recurso natural como es el agua, las costas, los suelos, etc. para el desarrollo de su economía o actividad productiva. Es de apreciar que muchas de dichas violaciones no fueron resueltas por la vía administrativa; aunque las sancionadas alegan que no cuentan con inversiones para ejecutar la solución del problema, lo que evidencia que la vía contravencional no resuelve la situación presentada y que utilizando como debía ser, la vía judicial, se hubieran obtenido otros resultados y otras soluciones; de lo que deviene la importancia de la acción de los organismos competentes en los conflictos medio-ambientales. Para demostrar tal apreciación haremos referencias a tres entidades en la provincia que han tenido una influencia en el impacto ambiental negativo con consecuencias plenamente peligrosas sin solución siendo éstas las siguientes, de la muestra tomada en ese período; de los procesos presentados ante la vía jurisdiccional en la sala de lo económico del Tribunal Provincial Popular de Granma, analizada la etapa del 2003 al 2006, la Sala de lo Económico hubo de conocer 18 procesos de infracciones al medio ambiente, donde se presentaron demandas por actos ilícitos en los que se incluyen procesos de quema de caña por imprudencia; penetración del ganado a las plantaciones (vianderas, frutales y cañeras) y poda indiscriminada. También se conocieron las demandas por contaminación de las aguas y los suelos, pero es de destacar que todas fueran presentadas a instancia de la parte afectada, notándose la ausencia de los organismos competentes como es el Ministerio de Ciencia y Tecnología, la Fiscalía General de la República y el Ministerio de la Agricultura, a pesar de las facultades otorgadas primero por el Decreto-Ley 223 del 15 de Agosto del 2001 sobre jurisdicción y competencia de las Salas de lo Económico [71] y luego por el Decreto-Ley 241 del 26 de septiembre del 2006 [72] en franca inobservancia de la voluntad estatal, estando presente la cantidad de infracciones de las regulaciones ambientales. Para mayor conocimiento, hay que destacar que en el año 2001 se aplicaron medidas contravencionales a diferentes instituciones del Estado, y que fue la mayor aplicación que se realizó en esta etapa, pues en el 2002 se redujo, en el 2003 se mantuvo en el rango de quince aplicaciones; observándose una disminución en el 2004 en que sólo se aplicaron siete, y el 2005 que se caracterizó por ser el año más bajo con cinco medidas o sanciones; lo que no se corresponde con la cantidad de infracciones que día a día se vienen cometiendo por las instituciones estatales, lo que 
demuestra una decadencia en cuanto al actuar administrativocontravencional que el organismo facultado como el CITMA viene obligado a realizar.[73]

Otro tanto se observa en las entidades que mayor incidencia tienen en la provincia, que sus efectos dañinos o contaminantes están por encima de los niveles de admisión establecidos por las convenciones de que Cuba es firmante; como son los vertimientos de residuales y líquidos agresivos de origen industrial que afectan a las zonas costeras y dañan las especies de plantas y animales presentes en el ecosistema marino y no marino; la no caracterización de los residuales que se vierten, incumpliendo con las normas cubanas de vertimientos, lo que ocasiona la contaminación de los ríos de la zona y de los suelos; falta de monitoreo con sistematicidad de los residuales líquidos y falta de un plan para los desechos peligrosos. Analizando todas las entidades sancionadas por las violaciones de la política ambiental en el período 2001-2005, podemos comentar que en su mayoría están fundamentadas en la obligación de hacer, cosa que como se ha explicado no resuelve tales problemas de afectación al medio ambiente, pues muchas de estas medidas que aplicó el CITMA, están en vías de solución porque requieren de un plan o proyecto de presupuesto para poderse materializar; de lo que se colige, como es nuestra intención, que debían de haberle promovido procesos económicos y que mediante una sentencia todo esto se hubiera resuelto, ya que por la lógica y razón ninguna resolución del Tribunal en estos casos siendo firme, puede ser cuestionada y amerita en la técnica jurídica el cumplimiento por cada uno de los implicados en el proceso o de lo contrario estaríamos en presencia de un delito de desobediencia ante el órgano jurisdiccional competente. El otro período analizado recoge la problemática en torno a la política ambiental dentro del tracto del 2006 al 2010, donde el comentario versa sobre las principales contravenciones en la provincia Granma en el período 2005-2010 reguladas por el CITMA y controladas a través de la inspección estatal, las que han sido:

- Extracción de arena: este incidente es cuestionable en la empresa constructora al presentarse fundamentalmente devastaciones mineras.

- Contaminación ambiental de los residuales de las industrias y por el trabajo manual. Este es un punto fundamental en cuanto a dichas incidencias. Es preciso tener en cuenta que cuando se habla de contaminación, de ésta se desprenden diversas aristas, ya sea agua, suelo, aire, ruido. En el período reconocido este ha sido el punto más vulnerable incluyendo la contaminación por ruido, está dado fundamentalmente por la falta de sonómetro en la provincia, una vez que se realicen actividades públicas o particulares, no se pueden tomar otras medidas que las de un llamado de atención o sugerencias.

- Contaminación por humo y mal olor. 
- Planes de manejo: antes de que se llevaran a cabo las remodificaciones de todos los policlínicos, éste era un tema de mucho tratamiento por vertimientos y salida de desechos peligrosos hacia la sociedad.

- Deforestación: la actividad de la forestación fue menos común en este período, sólo se dio a conocer un único caso, y fue dado precisamente con el bosquecito de las Caobas situado aquí mismo en Bayamo, pero con solución de carácter inmediato.

La actuación del CITMA con respecto a tales incidencias, teniéndose en cuenta que tal institución de la Administración Pública tiene como función principal exigir a las administraciones lo que está establecido aún y cuando existan contravenciones que no estén tipificadas. Para mejores resultados en el cuidado y protección del Medio Ambiente, sobre la base de la Ley número 81, haciéndola aplicar el gobierno y el CITMA exige para su cumplimiento en cada territorio. Tomando medidas administrativas, en relación con la aplicación del derecho administrativo sancionador, a tenor del Decreto Ley 200 [74]: en las llamadas paralizaciones definitivas o temporales, también conocidas como clausuras. (Basándose en el retiro de licencias ambientales por extralimitación en determinados impactos ambientales). Del año 2005 al 2009 no hubo ninguna clausura. A diferencia del año 2010, en este si se pronunció una paralización temporal, emitida por la Resolución 11 del 2010 [75], dado en el municipio de Pilón por extracción de áridos. En el período estudiado como medidas principales se aplicaron la amonestación, retiro de licencia en correspondencia con este último caso, y como medida accesoria y frecuentada la aplicación de la multa. [76] Los mecanismos para el conocimiento de dichas contravenciones por parte de este organismo de la Administración Central del estado han sido a través de la queja de la población y de los programas nacionales y territoriales de impacto ambiental, según planificación de trabajo. Hay otro aspecto que debemos resaltar, y es que se han puesto muchas multas institucionales y pocas personales, teniendo la carga de su pago el propio Estado a través de sus instituciones, lo que demuestra pasividad por los funcionarios de éstas en la solución del daño ambiental. [77] Con este artículo no presumimos criticar a los organismos de la administración pública estatal, como el CITMA, la Fiscalía y el MINAGRI [78]; aunque como organismos rectores en el desarrollo de su actividad tienen una responsabilidad por Ley, lo cual no ejercitan de manera adecuada según criterio de los autores, tal vez por desconocimiento o por falta de reglamentación de los organismos superiores donde puedan discernir y decidir con racionalidad y eficacia qué acciones pueden realizar en cada momento; si aplicar una contravención, una medida o establecer una demanda ante el órgano jurisdiccional competente.

En Cuba este movimiento de la historia ambiental fue casi desconocido; apenas un pequeño grupo de historiadores comenzó 
a preocuparse por incorporar en sus temáticas la problemática ambiental, pocos geógrafos y científicos naturales se interesan por incorporar la perspectiva histórica en sus investigaciones. Por otra parte se puede mencionar la creciente preocupación por la problemática medioambiental en el país, sobre todo a nivel estatal, aunque cada vez más como factor presente en la conciencia colectiva. Amén de que muchas personalidades como Alejandro de Humbolt,[79] y Antonio Núñez Jiménez [80], siempre estuvieron una visión en materia de protección ambiental. Esta justicia económica, como comúnmente se le conoce entre nosotros, era impartida, de manera unipersonal, por árbitros estatales que actuaban no sólo a requerimiento de parte afectada, sino también de oficio, pudiendo dar inicio a procesos arbitrales a partir del conocimiento fundado de determinados incumplimientos contractuales o de una afectación medioambiental. Estos órganos, más allá de su clara vocación jurisdiccional, participaban a la vez de la naturaleza y funciones propias de un órgano de control estatal, gozando de plenas facultades para convocar a cualquier entidad y realizar visitas de inspección a las mismas. Tal circunstancia última le imprimía un sello particular a la solución de litigios económicos relacionados con el medio ambiente y el uso racional de los recursos naturales, concediéndole un espacio importante como un protagonismo a los órganos de arbitraje estatal para su conocimiento y solución. La experiencia del funcionamiento de dichos órganos de arbitraje estatal en esta esfera contribuyó sensiblemente a la formación de una conciencia ambiental en el sector empresarial, tanto estatal como privado, fundamentalmente en el sector agropecuario, cuya actividad era y en gran medida continúa siendo, mayoritariamente, fuente u objeto de las violaciones de nuestro ordenamiento medio ambiental. Es así que a pesar de la natural inhibición de determinadas funciones anteriormente reconocidas al arbitraje estatal, las Salas de lo Económico han podido en estos últimos diecisiete años dar continuidad a la labor de solución de litigios relacionados con el medio ambiente, con determinada efectividad, procurando en todos los casos, por todos los medios a su alcance, el desarraigo de las causas que dan lugar a los mismos; lo cual se ha visto sensiblemente favorecido por la especial atención que a la problemática ambiental le han venido dispensando los órganos superiores del Estado y el Gobierno en nuestro país. Ello no obstante, pese a la expresada flexibilidad de las reglas de procedimiento arbitral, los jueces de lo económico han podido constatar la necesidad de contemplar en el nuevo ordenamiento procesal normas expresamente diseñadas para la justicia ambiental y claramente orientadas a dar respuesta a las situaciones de legitimación, práctica de pruebas, medidas cautelares y ejecución de fallos, que adolecieron de falta de precisión y obligaron a recurrir a construcciones integradoras. Este natural reclamo de la práctica judicial, a su vez, se ve reforzado con la recién adoptada Ley número. 81 "Del Medio Ambiente", de 11 de julio de 1997 [81], en virtud de la cual el conocimiento de los conflictos que surgen de su aplicación corresponde a las Salas de 
lo Económico de los tribunales populares, conforme lo establezca el Consejo de Gobierno del Tribunal Supremo Popular, sin perjuicio de que sean resueltas en sus propias jurisdicciones las materias civiles, penales, contencioso-administrativas y administrativocontravencional. En este sentido se impone tomar en cuenta que, de conformidad con la expresada Ley del Medio Ambiente [82], es forzoso considerar legitimados para ejercitar las acciones correspondientes ante los tribunales no sólo a las personas o entidades perjudicadas, sino adicionalmente a la Fiscalía General de la República y al propio Ministerio de Ciencia, Tecnología y Medio Ambiente; supuestos estos en los que no se hace coincidir el titular del derecho sustantivo ejercitado y la parte procesal que lo hace actuar, nueva forma de legitimación introducida por la ley medio-ambiental al establecer, taxativamente, quien es el que puede deducir la correspondiente pretensión procesal. Es así que, con arreglo a lo establecido en la Ley número 83, también de 11 de julio de 1997, "De la Fiscalía General de la República" [83], le corresponde a ésta ejercer en representación del Estado las acciones judiciales que correspondan conforme a la legislación vigente, en función del interés social, sin perjuicio de las facultades que la propia ley le reconoce para realizar verificaciones fiscales con el fin de comprobar el cumplimiento de la Constitución y demás disposiciones legales, con un carácter eminentemente preventivo y asegurador de la observancia de la legalidad, de incuestionable trascendencia al ordenamiento medio-ambiental.

Esto aun cuando no deja de estar por resolver de forma concordante en la preceptiva procesal de las expresadas salas de justicia, no deja de conectar, sin embargo, con la experiencia asumida de los procesos de oficio en los marcos del arbitraje estatal, en estado de latencia en la vigente norma procesal. Otro tanto cabría afirmar, con sus matices, respecto a las acciones ejercitables por el CITMA, en tanto organismo rector del sistema de protección medio-ambiental. Estas dos puertas de acceso, a su vez, pudieran ser igualmente portadoras de intereses directos de otros actores individuales o colectivos, no reconocidos de forma expresa en la ley, y que pudieran hacer representar sus intereses por tales instituciones en los procesos ante las Salas de lo Económico de los Tribunales. No es tal el caso aún de las medidas cautelares 0 asegurativas, las que se encontraban fuera del alcance de los órganos de arbitraje estatal y, consiguientemente, de las Salas de lo Económico, aspecto éste de marcada relevancia instrumental en el proceso y de especial significación por la diversidad y alcance de las medidas a adoptar con este carácter en el conflicto ambiental. Es de advertir, sin embargo, que de conformidad con el artículo 72 de la propia Ley número 81 [84] "[...] para asegurar los resultados del proceso o para evitar que se siga causando un daño, se podrán solicitar y adoptar las medidas que franqueen la legislación procesal vigente", lo cual es posible conectar con el hecho de que en su Disposición Especial Primera; al encomendar a estas salas de justicia el conocimiento de dichos conflictos, indicó que ello habrá de ser de conformidad con lo que 
establezca el Consejo de Gobierno del Tribunal Supremo Popular, a quien le estaría dado abrir la posibilidad a esta jurisdicción para acudir, para ello, a las normas procesales contenidas en la Ley número 7 de 1977, "Ley de Procedimiento Civil, Administrativo y Laboral" [85]. Como solución transitoria hasta tanto se adoptara la Ley Procesal de las Salas de lo Económico; lo que quedó resuelto mediante el Decreto-Ley número 241 de 26 de Septiembre de 2006, modificativo de la Ley de Procedimiento Civil, Administrativo y Laboral, el cual se denominó Ley de Procedimiento Civil, Administrativo, Laboral y Económico. [80] En cuanto a los medios de prueba, las reglas de procedimiento arbitral en ese entonces, de aplicación por estas Salas, le confirieron un protagonismo importante al Tribunal, sin límites o encerramientos temporales y con amplias facultades para requerir su presentación por las partes o terceros y plena libertad de apreciación, pudiendo analizarlas globalmente, con toda objetividad y criterio racional, teniendo en cuenta el conjunto de las circunstancias del caso, sin que quepa atribuir a ninguna prueba valor preestablecido alguno. La carga de la prueba, sin embargo parece requerir un tratamiento especial que, en algunos supuestos, pudieran llevar a su inversión. En lo esencial ello es congruente con el objetivo último, anteriormente de los procesos ante los órganos de arbitraje estatal y actualmente de las Salas de lo económico, que lo era y lo continúa siendo el desarraigo de las verdaderas causas que pudieran haber dado lugar al conflicto, lo cual, en nuestra opinión, ha de ser teleológicamente un objetivo cardinal y orientador de todo proceso medio-ambiental. En el proceso, igualmente, el tribunal tiene la posibilidad de adoptar o disponer determinadas actuaciones preparatorias de la comparecencia comprendida a la de decidir la inclusión de terceros, devolver la demanda en caso de acumulación de acciones para su presentación por separado cuando así resulte aconsejable, citar a las partes para precisar aspectos concretos del caso o exigir de las mismas declaraciones, escritos y documentos suplementarios y otras pruebas, así como decidir si se cita o no a que declaren en su día funcionarios de entidades que no sean parte en el proceso, o exigir documentos o dictámenes de la misma. Son éstas, actuaciones que a nuestro juicio pueden ser reasumidas en nuestro ordenamiento procesal de lo económico y atemperadas a los requerimientos y particularidades del los procesos del medio ambiente. En un sentido u otro, es cierto que las derogadas reglas de procedimiento de aplicación por las Salas de lo Económico en nuestro país, no fueron diseñadas ni concebidas tomando en consideración las exigencias de un proceso medio-ambiental, por lo que, estando justamente inmersos en el procedimiento ordenado mediante el Decreto-Ley 241 [86], tenemos el claro propósito de que puedan contribuir a elevar la ductibilidad, seguridad y eficacia de sus preceptivas en estos procesos. Es criterio de los autores que se debe pensar que cuando sea constituida la sala que conocerá los conflictos sobre medio ambiente o de justicia ambiental como también se le denomina, será un escenario ideal para insertar los delitos como resultado de la conflitualidad medioambiental. Sí 
tenemos en cuenta que ahora hay países que han especializado a Juristas en Fiscalías de corte ambientalista y se han constituido Tribunales en materia de medio ambiente, definidos dentro de su derecho interno, como es el caso en Centroamérica de México y en Latinoamérica de Chile, sumando la revisión en el orden penal de los delitos ambientales.

\section{CONCLUSIONES}

- La problemática en el incumplimiento de la política en materia de protección al medio ambiente persiste, al no existir una cultura del impacto por los actores principales dentro de la Administración Pública cubana en la macro, meso y micro estructuras de la Administración Pública en relación con la dimensión social del problema, que pudiera ir decidiéndose el estudio en el sistema de Educación Superior las carreras de ingeniería ambiental y la de licenciatura en ciencias ambientales.

- Dentro del ordenamiento jurídico cubano no existe una normativa sobre la responsabilidad ambiental, que le permita exigir a la Administración Pública el incumplimiento de estas conductas, con la debida solución adecuada a la problemática ambiental tratada hacia las personas jurídicas y naturales. (La carga de responsabilidad del ciudadano ambiental).

- El nuevo órgano de control que se ha encargado para exigir y hacer cumplir lo relacionado con la inacción sobre los problemas ambientales, es inconstitucional, al no aparecer en la Constitución cubana, que permitirá con la ejecución de la auditoría ambiental certificar a las empresas con las tecnologías limpias, haciéndola competitiva con estándares internacionales en materia comercial.

- Persiste la falta de una adecuada cultura ambiental respecto al impacto, a pesar de que aun se trabaja por los actores con competencia y jurisdicción en crear una conciencia jurídica ambiental, aun a criterio de los autores no lograda, pues no hay percepción del riesgo.

- Es de suma importancia trabajar para minimizar la actual fragmentación en materia de normativas medioambientales vigentes, que de una manera u otra dificultan la labor de los actores con competencia y jurisdicción que ejercen acciones en materia de control estatal.

- Es criterio de los autores que la justicia ambiental debe ventilarse en la vía jurisdiccional en los tribunales ambientales, y no en la actual sala de lo económico, donde puedan insertarse especialistas en materia medioambiental que ayuden a darle una solución adecuada a la problemática ambiental tratada.

- Consideramos que la actual justicia ambiental cubana utiliza de forma mayoritaria la aplicación del Derecho Administrativo 
Sancionador por parte de los agentes de la Administración Pública, en el enfrentamiento de la problemática ambiental.

\section{REFERENCIAS BIBLIOGRÁFICAS Y NOTAS ACLARATORIAS}

[1] MANUAL PARA LA FORMACIÓN DEL MEDIO AMBIENTEEditorial LEX NOVA. España. pág. 42. El cual hace referencialmente una explicación pormenorizada en la formación medioambiental, y en particular la auditoría ambiental, como auditoría tipo en la protección medioambiental. [2] BRAÑES-BALLESTEROS, Raúl. (1994). Manual de Derecho Ambiental Mexicano. Fondo de Cultura Económica. México. Explica (pág. 18) "[...] la expresión "medio ambiente [...]" presentaba una cierta redundancia interna, cuando ella fue difundida a partir de 1972 y como una secuela idiomática de la ya histórica Conferencia de las Naciones Unidas sobre el Medio Humano (celebrada ese año en la ciudad de Estocolmo). En efecto, el centro de interés de esa Conferencia se fue desplazando del "medio humano" (human environment or environnement humain) al "medio" en general (environment or environnement) por lo que se estimó necesario sustituir la expresión española "medio humano" por otra más apropiada. Pero, en vez de sustituirla por "medio" o "ambiente", se prefirió acuñar por razones que desconocemos la nueva expresión "medio ambiente", que en nada contribuía a hacer explícita la idea de "medio" o "ambiente" en general y que, en cambio, se prestaba para las numerosas críticas que se le han hecho [...]" Sin embargo, reconoce el propio autor que el término ha adquirido "una cierta legitimidad", que la Real Academia Española le reconoce, y al efecto cita su 20a Edición (1984) en la que "medio ambiente" aparece incorporado como una expresión de la lengua española que denota "el conjunto de circunstancias físicas que rodean a los seres vivos" y, por extensión, el "conjunto de circunstancias físicas, culturales, económicas, sociales, etc., que rodean a las personas" [3] JAQUENOD DE ZSOGON, Silvia. (1989) En "El Derecho Ambiental $y$ sus Principios Rectores" MOPU. España. [4] Ley número 33 de 10 de enero de 1981, "De Protección del Medio Ambiente y del Uso Racional de los Recursos Naturales. Actualmente ya derogada dentro del derecho interno cubano, sustituida por la Ley número 81 de 1997, Ley del Medio Ambiente, en vigencia.

[5] DECRETO LEY NO.1 de 24/02/1977, (Gaceta Oficial Ordinaria No.6 de 26/02/1977), establece la extensión del Mar Territorial Por su parte el Decreto Ley No.2 de 24/02/1977, (Gaceta Oficial Ordinaria No.6 de 26/02/1977), define la Zona Económica de la República de Cuba. [6] GLOWKA, Lile, et al. (s.f.). Persiguiendo el objetivo de destacar el uso sostenible dentro de la conservación, es frecuente utilizar la expresión "conservación y uso sostenible" de forma tal que ha adquirido vida propia, más no debemos perder de vista que la 
utilización sostenible de los componentes de la diversidad biológica es un elemento esencial cuando a conservación de los mismos nos estamos refiriendo. La conservación ha dejado de ser una actitud contemplativa, pasiva, idílica para convertirse en un concepto que expresa la interrelación constante dinámica, armónica entre el hombre y el medio natural en el cual esta insertado. Si algún motivo podemos ver en el distingo que se ha hecho entre conservación y sostenible, lo podemos encontrar en el argumento expuesto por la UICN en su Guía de Convenio sobre la Diversidad Biológica elaborado cuando nos dice "La separación de los conceptos tiene su origen en los deseos de los países en desarrollo que pretendían enfatizar la importancia de utilizar los componentes de la diversidad biológica de una manera sostenible [...] estaban particularmente preocupados que el término conservación si se utilizaba en forma independiente podría poner el énfasis en los aspectos vinculados con la preservación" . "Guía de Convenios sobre la Diversidad Biológica", Centro de Derecho Ambiental de la UICN, Programa de la Biodiversidad de la UICN, UICN. 1996: pág. 10. [7] ENGELS, Federico (s.f.). "Introducción a la dialéctica de la naturaleza". Obras Escogidas en dos tomos, Tomo 2, págs. 57-58. Editora Ciencias Sociales. La Habana. Cuba pág. 58. Editora Ciencias Sociales. La Habana. Cuba. En la que se destaca por este clásico de la filosofía marxista leninista la necesidad de proteger la naturaleza por el hombre, de aprender a convivir con la misma. Material bibliográfico de estudio en las universidades cubanas, en filosofía. [8] MARTÍNEZ, Eleuterio. (s.f.) No existe una clara definición de lo que es la vida. Biodiversidad. Suma total de vida. Tomo I; pág.60. Editora Ciencias Sociales. La Habana. Cuba. [9] DICCIONARIO DE LA REAL ACADEMIA DE LA LENGUA. España. 2011. [10] NORMAS TÉCNICAS AMBIENTALES ISO 14001. Sistemas de gestión medioambiental. Oficina Nacional de Normalización. República de Cuba. La Habana. [11] ENGELS, Federico: obra citada, pp. 60-63. Editora Ciencias Sociales. La Habana. Cuba. [12] LENIN, Vladimir llich. (s.f.)"En torno a la dialéctica”, Obras Escogidas", Tomo IV, pp. 368-369. Editora Ciencias Sociales. La Habana.

Cuba.

[13] ENGELS, Federico (s.f.). p. 58. La Habana. Cuba. [14] COSCULLUELA, J.A. (s.f.). "Cuatro años en la Ciénaga de Zapata", p. 212. Editora Ciencias Sociales. La Habana. Cuba. [15] Ibídem, pág. 205. [16] Ibídem, pág. 212. [17] BROWN, Lester, R. (1993). "La situación en el mundo", Wordwatch Institute. [18] BRUNDTLAND, G. H. et al. (1990). Nuestro futuro común. Comisión Mundial sobre Medio Ambiente y Desarrollo, 1987, Londres, Oxford University Press. [19] Desde 1998, la Sra. Gro Brundtland es Directora de la UNICEF. Sistema de Naciones Unidas. 
[20]

Ibídem

no.

21.

[21] RODAS MONSALVE, Julio César: "Fundamentos constitucionales del Derecho Ambiental Colombiano": pp. 5-6. [22] SERIE DE DOCUMENTOS LEGISLATIVOS SOBRE DERECHO AMBIENTAL. ,(1995) PNUMA. pág. 11. Sistema de Naciones

Unidas.

[23] MARTÍNEZ, Eleuterio (s.f.) obra citada, pág. 170. Editora Ciencias Sociales. La Habana. Cuba. [24] PILIPENKO, N. (1986). "Dialéctica de lo contingente y lo necesario“, Editorial Progreso, Moscú: pág. 179. [25] HOLBACH, obra citada, pág. 79. Enciclopedista francés que se anticipo a su tiempo, al señalar la problemática ambiental si el hombre no cumplía las reglas de equilibrio al interactuar con el medio ambiente, donde sus señalamientos están presentes hoy día más que nunca. [26] Ibídem no. 1 págs. 47-49. [27] MCNEILL, John R. (2003). "Historia y Teoría" pp. 5- 43 [28]Ibídem no. 28.

[29] CUNILL, Pedro. "Variables geo históricas sociales en los procesos de degradación del uso rural de la tierra en América Latina".

[30] PITA-JIMENEZ, Néstor. Informe de tesis de especialidad en derecho civil y familia. "La inacción en la solución de los conflictos ambientales". Disponible en la Facultad de Derecho. Universidad de Oriente. La Habana. Cuba. Destacado jurista que dedicó muchos años a trabajar en el Tribunal Popular Provincial de Granma, y quien ejerció como Presidente de la sala de lo económico, experto conocedor de la solución de los problemas ambientales a la luz del derecho procesal económico de Cuba y de otros temas relacionados con el trabajo. [31] Ibídem no. 31. [32] Ibídem no. 31. [33] Ibídem no. 31. [34] Ibídem no. 31. [35] Ver dentro del sistema de Naciones Unidas. CEPAL: Comisión Económica para conocer los asuntos de la América Latina, así como el crecimiento en esta materia en tal región del planeta. [36] Consultar texto del informe aprobado en la Cumbre de Río de Janeiro. (1995). Brasil. Donde los Estados a través de una serie de documentos, tratados, convenios, marcos, se pusieron de acuerdo y firmaron, en pos de mitigar con sus acciones negativas, el daño que se está realizando al medio ambiente a escala global, cuestión esta aún sin cumplirse, véase el próximo evento Río+20, donde se volverán a reunir estadistas para analizar lo acontecido hasta la fecha y qué nuevas medidas se tomarán para mitigar esta problemática y preservar la especie humana. De la cuál el mundo quedó decepcionado, pues los países más ricos no firmaron los tratados relacionados con el Derecho Ambiental Internacional, a pesar de las alertas que el concláve Rio+20 informó al mundo, con particular interés la firma del Protocolo de Kyoto, para mitigar la emisión de gases que producen el actual calentamiento global, del cuál países como Estados Unidos, Japón, y Rusia, entre otros han 
decidido no firmar y retirarse, el que vencerá en diciembre 2012, sin que exista aún que medidas se adoptarán para mitigar la actual situación en que se encuentra la tierra. [37] Ibídem no. 31.

[38] Ibídem no. 31.

[39] CONSTITUCIÓN DE LA REPÚBLICA DE CUBA. (1976). Disponible en la página web del Ministerio de Justicia. www.gacetaoficial.cu. Aparece señalado el artículo 27, el que señala la responsabilidad estatal en la protección del medio ambiente.

[40] Ley número 33, del medio ambiente, derogada por la Ley Número 81, Ley del Medio Ambiente de la República de Cuba. Disponible en el sitio web del Ministerio de Justicia: www.gacetaoficial.cu. Antecesora de la actual norma marco en materia medioambiental, la que sentó pautas para el desarrollo en materia legislativa en torno a la protección del medio ambiente. [41] Consultar serie de normas que establecieron el SISTEMA DE ARBITRAJE ESTATAL en Cuba, precedente de la actual sala de los delitos económicos, del Tribunal Popular. [42] Ibídem no. 46 [43] PITA-JIMÉNEZ, Néstor(s.f.). Informe de tesis de especialidad en derecho civil y familia. "La inacción en la solución de los conflictos ambientales". Disponible en la Facultad de Derecho. Universidad de Oriente. La Habana. Cuba. Destacado jurista que dedicó muchos años a trabajar en el Tribunal Popular Provincial de Granma, y quien ejerció como Presidente de la sala de lo económico, experto conocedor de la solución de los problemas ambientales a la luz del derecho procesal económico de Cuba y de otros temas relacionados con el trabajo.
[44] Ibídem
no.
48.

[45] LINEAMIENTOS DEL PARTIDO COMUNISTA DE CUBA. (2011). 6to congreso. Publicado por el órgano de prensa del propio Partido.

[46] Conferencia del Partido Comunista de Cuba. (2012).Publicado por el órgano de prensa cubana del propio Partido. [47] PITA-JIMÉNEZ, Néstor.(s.f.) Informe de tesis de especialidad en Derecho civil y familia. "La inacción en la solución de los conflictos ambientales". Disponible en la Facultad de Derecho. Universidad de Oriente. La Habana. Cuba. Destacado jurista que dedicó muchos años a trabajar en el Tribunal Popular Provincial de Granma, y quien ejerció como Presidente de la sala de lo económico, experto conocedor de la solución de los problemas ambientales a la luz del derecho procesal económico de Cuba y de otros temas relacionados con el trabajo aquí abordado por los autores.

[48] Ley Número 81, Ley del Medio Ambiente. Disponible en el sitio web www.gacetaoficial.cu, del Ministerio de Justicia, La Habana. República de Cuba.

[49]

[51] lbídem

Ibídem

lbídem no.

no.

no.
52

52

52 
$\begin{array}{llll}{[52]} & \text { Ibídem } & \text { no. } & 52 \\ {[53]} & \text { Ibídem } & \text { no. } & 52 \\ {[54]} & \text { Ibídem } & \text { no. } & 52\end{array}$

[55] Ibídem no. 52

[56] Ley Número 59, Código Civil, el mismo establece la responsabilidad civil en relación con la exigencia de la responsabilidad medioambiental a los actores involucrados dentro del ordenamiento jurídico cubano. [57] Ibídem no. 52 [58] Ley No 81, Ley del medio ambiente, donde se establece que el órgano de la Administración Pública con competencia y jurisdicción en materia medioambiental es el Ministerio de Ciencias, Tecnología y Medio Ambiente, sustituyendo a las disposiciones de la derogada Ley número 33. [59] Disposición jurídica que entra a proteger el bien jurídico ambiental, establecidas por la Administración Pública del Estado cubano, complementando las regulaciones dispuestas en la Ley marco, Ley no. 81, Ley del medio ambiente.

[60]

lbídem

no.

64.

[61] Ibídem no. 64.

[62] PITA-JIMÉNEZ, Néstor. (s.f.). Informe de tesis de especialidad en Derecho civil y familia. "La inacción en la solución de los conflictos ambientales". Disponible en la Facultad de Derecho. Universidad de Oriente. La Habana. Cuba. Destacado jurista que dedicó muchos años a trabajar en el Tribunal Popular Provincial de Granma, y quien ejerció como Presidente de la sala de lo económico, experto conocedor de la solución de los problemas ambientales a la luz del derecho procesal económico de Cuba y de otros temas relacionados con el trabajo.

$\begin{array}{llll}{[63]} & \text { Ibídem } & \text { no. } & 67 . \\ {[64]} & \text { Ibídem } & \text { no. } & 67 . \\ {[65]} & \text { Ibídem } & \text { no. } & 69\end{array}$

[66] Ibídem no. 69

[67] Norma jurídico administrativa que dispone dentro del territorio nacional el órgano con encargo estatal (CITMA), la inspección estatal en materia medioambiental. La que se ejecuta según cronograma de trabajo anual en relación con la problemática ambiental existente en cada territorio con relación a la división política administrativa del país. [68] Ibídem no. 73. [69] Datos obtenidos en la Delegación Territorial del CITMA, Granma, en fecha 3 de noviembre de 2011. Por parte de la oficina de gestión ambiental, donde se ejecutan las inspecciones ambientales

[70]

Ibídem

no.

76 
[71] Científico de origen alemán, quien realizara estudios en materia medioambiental en Cuba, quien por sus resultados fue en su momento catalogado como el segundo descubridor de Cuba, en relación con los resultados científicos que dio a conocer en materia medioambiental, siendo reconocida su labor en este sentido por parte del Estado cubano. [72] Científico cubano de prestigio internacional, dedicado en su vida a la investigación y protección del medio ambiente, quien trabajó en el CITMA, organismo de la Administración Pública cubana dedicado a la protección del medio ambiente, actualmente en reconocimiento a su labor existe en el país una Fundación con su nombre dedicada a seguir el trabajo que éste inició. [73] PITA-JIMÉNEZ, Néstor.(s.f.) Informe de tesis de especialidad en derecho civil y familia. "La inacción en la solución de los conflictos ambientales". Disponible en la Facultad de Derecho. Universidad de Oriente. La Habana. Cuba. Destacado jurista que dedicó muchos años a trabajar en el Tribunal Popular Provincial de Granma, y quien ejerció como Presidente de la sala de lo económico, experto conocedor de la solución de los problemas ambientales a la luz del derecho procesal económico de Cuba y de otros temas relacionados con el trabajo. $\begin{array}{llll}\text { [74] } & \text { Ibídem } & \text { no. }\end{array}$ $\begin{array}{llll}{[75]} & \text { Ibídem } & \text { no. }\end{array}$ [76] Ibídem no. 88

[77] PITA-JIMÉNEZ, Néstor. (s.f.). Informe de tesis de especialidad en Derecho civil y familia. "La inacción en la solución de los conflictos ambientales". Disponible en la Facultad de Derecho. Universidad de Oriente. La Habana. Cuba. Destacado jurista que dedicó muchos años a trabajar en el Tribunal Popular Provincial de Granma, y quien ejerció como Presidente de la sala de lo económico, experto conocedor de la solución de los problemas ambientales a la luz del derecho procesal económico de Cuba y de otros temas relacionados con el trabajo. [78] Ibídem número 93. [79] Modificación realizada a la actual Ley de trámites cubana, Ley número 7 , de procedimiento civil, administrativo y laboral, incluyéndosele el 5to libro, que trata la solución de los conflictos económicos por parte del Tribunal Popular en provincias, a través de la sala de lo económico, quien conoce de los conflictos en materia de medio ambiente. [80] Científico cubano que se dedicó por muchos años dentro de la Academia de Ciencias de Cuba, actual Ministerio de Ciencias, Tecnología y Medio Ambiente (CITMA), a estudiar la naturaleza cubana y a trabajar por preservar la misma. Hoy en día en Cuba existe una Fundación dedicada a seguir la obra científica del profesor

[81] Ibídem número 48.

[82] Ibídem número 48.

[83] Ley de la Fiscalía General de la República de Cuba. Le permite a los fiscales velar por el cumplimiento de la Legalidad Socialista, en la arista ambiental lo ejercitan a través de la 
Verificación Fiscal en el sector estatal y no estatal dentro del territorio

nacional.

[84] Ibídem número 58.

[85] Ley tramitadora en materia procedimental que permite a los Juristas cubanos acudir al foro jurídico a resolver los litigios en materia civil, administrativo, laboral; siendo modificada por el Decreto Ley número 241, donde se le incluye el proceso económico.

[86] Ibídem número 79.

\section{BIBLIOGRAFÍA}

- Bolaños, F. (1990). Impacto biológico, problema ambiental contemporáneo. Instituto de Biología. La Habana. Cuba.

- Brañes, Raul (2000). Memorias del Seminario/Taller: Solución de conflictos ambientales en la vía judicial. Edición CITMA- Universidad de Tulano. México D. Ciudad de La Habana.

- (2000). Manual de Derecho Ambiental Mexicano. Edición CITMA. Ciudad de La Habana.

- Castro-Ruz, Dr. Fidel (2008). La injustificable destrucción al medio ambiente. Reflexiones. La Habana. Cuba.

- Carmona-Lara, M. (s.f.). Aspectos jurídicos de la auditoría ambiental en México. México.

- (s.f.). Derecho ecológico. Escuela Libre de derecho. México.

- Caraballo-Maqueira, Dr.C. Leonel (s.f.). El pensamiento ambiental cubano. Dirección Jurídica del CITMA. La Habana. Cuba.

- Calderón-Bertheneuf, J. L. (s.f.). La auditoría ambiental en México. Subprocurador de auditoría ambiental de PROFEPAS. México.

- Caferrata, Nestor (s.f.). La responsabilidad por daño ambiental. Investigador Universidad de El Salvador. Instituto de Ecología. Facultad de ciencias jurídicas. Universidad de El Salvador.

- (s.f.). El principio precautorio. Facultad de ciencias jurídicas. Universidad de El Salvador.

- Colectivo de autores. (2002). Temas de Derecho Administrativo. Editora Félix Valera. Universidad de La Habana.

- Colectivo de autores. (2005). Derecho Ambiental Cubano. Editorial Félix Varela. Universidad de La Habana. Cuba.

- Colectivo de autores. (1987). Higiene del Medio. Texto Básico, tomo II. Editorial Revolución. Cuba. Capítulo "Medio Ambiente y la Inspección Sanitaria Estatal".

- Colectivo de autores. (2000). Módulo de formación ambiental básica: Diversidad biológica y contaminación y gestión de residuos. Manejo sostenible de suelos. Ordenamiento 
ambiental. Ecosistemas de Manglar. Editora CITMA. La Habana. Cuba.

- Lineamientos VI congreso del PCC. (2011). Editora Política. Partido Comunista de Cuba. Cuba.

- Colectivo de autores. (2003). Cuba y su Medio Ambiente después del Milenio. Editorial CESIGMA. Editorial Científico Técnica. pp. 70-80.

- CITMA-PNUMA (1995). Principales legislaciones ambientales existentes en Cuba.

- CITMA (2011- 2015). Situación ambiental cubana.

- Cruz-Sardiñas, Teresita. (1995). Recursos renovables y no renovables y del patrimonio cultural. CITMA. La Habana. Cuba.

- $\quad$ : (1997). Marco político. Institucional y jurídico de la protección de los recursos marinos en Cuba. La Habana. Cuba.

- Diccionario de términos ambientales. (2000). Camacho Barreiro, A. et al. Publicación acuario. La Habana. Cuba.

- Estrategia Ambiental Nacional. CITMA (2011-2015) Cuba.

- Estrategias Territoriales De Medio Ambiente y Ciencia e Innovación Tecnológica. (2011-2015). Granma.

- Engels, Federico. (1979). Introducción a la dialéctica de la naturaleza. Obras Escogidas en dos tomos. Tomo 2. Editorial Ciencias Sociales. Cuba.

- Eguzquiza-Pereda, C. (2001). Auditoría medioambiental. México.

- Fernández-Rubio, L. Dr. C. Ángel. (1999). Ley no. 81 en más de 150 preguntas y respuestas. Editora MINJUS. La Habana. Cuba.

- . (1999). Legislación: una herramienta. Editorial Academia. La Habana. Cuba. pp. 13-135.

- _ (2000). La legislación ambiental contemporánea: logros y fracasos, algunas reflexiones críticas. Editorial Academia. La Habana. Cuba.

- (2002). Medio ambiente, desarrollo y derechos humanos. Editorial Academia. La Habana. Cuba.

- (2011). Diccionario de términos ambientales. Editorial Ciencias Sociales. La Habana. Cuba.

- Fournier-Duarte, Niurka. (2000). El daño ambiental a la luz de la justicia económica cubana. ONBC. La Habana. Cuba.

- Hernández-Torres, V. (1995). Acciones y propósitos de la actual legislación cubana. CITMA.

- González-Novo, T. (1998). Cuba su medio ambiente después de medio milenio. Editorial Científico-Técnica. Editora: Instituto del Libro. CESIGMA. La Habana. Cuba. pp.15-30

- Manual de formación ambiental. (2003). Comunidad Europea. Editora LEX NOVA. España.

- Mejías-Rodríguez, C. (2000). El ámbito procesal del derecho penal económico en Cuba. Centro de investigación derecho penal económico. La Habana. Cuba. 
- Garcini-Guerra, H. (1978). Derecho Administrativo. Editora Pueblo y Educación. La Habana. Cuba.

- García Enterría. (1999). Derecho Administrativo. España.

- LEE, H. (1998). Manual de Auditoría Medio Ambiental. Higiene y Seguridad. Segunda Edición. EUA.

- Toledano Cordero, Dra. C. D. (s.f.). La responsabilidad civil por daños ambientales. Universidad de La Habana.

- Pérez-Fuentes, G. (2000). La responsabilidad civil por daños al medio ambiente en el derecho comparado. Universidad de Tabasco. México.

- Viamontes-Guilbeaux, Dra. C. E. (1998). Compendio de Legislación Ambiental. Tomo I. Editorial Félix Várela. Cuba.

- . (2001). La responsabilidad administrativa ambiental. Universidad de La Habana. Cuba.

- Velazco-Caballero, F. (2002). La protección al medio ambiente ante el tribunal europeo de derechos humanos. España.

\section{Normas jurídicas consultadas:}

- Constitución de la República de Cuba. (1976). Editora Ministerio de Justicia. La Habana. Cuba.

- Ley No. 1. Ley de protección al patrimonio cultural. (1977). Editora Ministerio de Justicia. La Habana. Cuba.

- Ley No. 2. Ley de los monumentos nacionales y locales. (0408-1977). Editora Ministerio de Justicia. La Habana. Cuba.

- Ley No. 41. Ley de la Salud Pública. (13-07-1983). Editora Ministerio de Justicia. La Habana. Cuba.

- Ley No. 59. Código Civil. (16-07-1987). Editora Ministerio de Justicia.

- Ley No. 62. Código Penal. (29-12-1987). Editora Ministerio de Justicia.

- Ley No. 65. Ley forestal. (1998). Editora Ministerio de Justicia. La Habana. Cuba.

- Ley No. 73. Ley del sistema tributario. (1994). Editora Ministerio de Justicia. La Habana. Cuba.

- Ley No. 76. Ley de Minas. (1994). Editora Ministerio de Justicia. La Habana. Cuba.

- Ley No. 77. Ley de la Inversión Extranjera. (1994). Editora Ministerio de Justicia. La Habana. Cuba.

- Ley No. 81 Ley del Medio Ambiente. Editora Ministerio de Justicia. La Habana. Cuba. Disponible en el sitio web: www.gacetaoficial.cu

- Ley No. 107. De la Contraloría General de la República. (s.f.). Editora Ministerio de Justicia. La Habana. Cuba.

- Decreto Ley No. 99 de 1987. Sistema de Tratamiento a las Contravenciones Personales. Editora Ministerio de Justicia. La Habana. Cuba. 
- Decreto Ley No. 200 de las contravenciones en materia ambiental. Editora Ministerio de Justicia. La Habana. Cuba.

- Decreto Ley No. 212 de la Zona costera. Editora Ministerio de Justicia. La Habana. Cuba.

- Decreto Ley No. 241. Modificaciones a la LPCALE. Editora Ministerio de Justicia. La Habana. Cuba.

- Decreto No. 42. (24-05-1979). Reglamento General de la Empresa Estatal. Editora Ministerio Educación Superior. Editora Ministerio de Justicia. La Habana. Cuba.

- Decreto No. 228. (1-11-1997). Contravenciones personales de las normas presupuesto, control interno, y la contabilidad, Decreto Ley de auditoría, Editora Finanzas al Día, Tomo I y II. Multas. Ministerio de Finanzas y Precios. Editora Ministerio de Justicia. La Habana. Cuba.

- Decreto Ley No. 99. Contravenciones Personales. G.O. Extraordinaria No. 12. (25-12-1987).

- Decreto Ley No. 129. De extinción del Sistema de Arbitraje Estatal. G.O. Ordinaria No.9. (19-08-1991).

- Decreto Ley No. 136. Del Patrimonio Forestal y la Fauna Silvestre. G.O. Extraordinaria No.2. (5-03-1993).

- Decreto Ley No. 137. De la Medicina Veterinaria. G.O. Ordinaria No.6. (19-04-1993).

- Decreto Ley No. 138. De las aguas terrestres. G.O. Ordinaria. No. 9. (2-07-1993)

- Decreto Ley No. 147. De la reorganización de los OACE. G. O. Extraordinaria No.2. (21-04-1994).

- Decreto Ley No. 153. De las regulaciones de la sanidad vegetal. G.O. Ordinaria No. 11. (12-09-1994).

- Decreto Ley No. 159. De la Auditoría. G. O. Ordinaria No. 20. (3-07-1995).

- Decreto Ley No. 164. Reglamento de Pesca. G.O. Ordinaria No. 26 (22-07-1996).

- Decreto Ley No. 165. De las Zonas Francas y Parques Industriales. G. O. Ordinaria No.26. (22-07-1996).

- Decreto Ley No. 170. Sistema de medidas de la Defensa Civil. G.O. Ordinaria No.16. (19-05-1997).

- Decreto Ley No. 200 Contravenciones en materia de medio ambiente. G.O. Ordinaria No.83. (23-12-1999).

- Decreto Ley No. 201 Sistema Nacional de Áreas Protegidas. G.O. Ordinaria No.84. (24-12-1999).

- Decreto Ley No. 219. De la Auditoría Gubernamental. G.O. Extraordinaria No.14. (25-04-2001)

- Decreto Ley No. 223. Jurisdicción y competencia de las Salas de lo Económico. TSP. G.O. Extraordinaria No.10. (1608-200).

- Decreto Ley No. 230. De Puertos. G.O. Ordinaria No.38. (1804-2001).

- Decreto Ley No. 272. Contravenciones en materia de ordenamiento territorial y de urbanismo. G.O. Ordinaria No. 2. (21-02-2001).

- Decreto Ley No. 281. Del Sistema de Información del Gobierno. G.O. Extraordinaria No .10. (23-02-2011). 
- Decreto No. 100. De la Inspección Estatal. G.O. Ordinaria No. 14. (10-02-1982).

- Decreto No. 104. Control Sanitario Internacional. G.O. Ordinaria No. 38.(6-05-1982).

- Decreto No. 139. Reglamento de la Ley de la Salud Pública. G.O. Ordinaria No. 12. (5-12-1985).

- Decreto No. 169. Contravenciones Sanidad Vegetal. G.O. Ordinaria No.5. (6-051992).

- Decreto No. 174. Registro ganado mayor y razas puras. G.O. Ordinaria No. 13.(31-10-1992).

- Decreto No. 179. Protección, uso y conservación de los suelos y sus contravenciones. G.O. Ordinaria No. 4. (26-021993).

- Decreto No. 181. Contravenciones de las regulaciones sobre la medicina veterinaria. G.O. Ordinaria No. 7. (12-5-1993).

- Decreto No.199. Contravenciones de las regulaciones para la prestación y uso racional de los recursos hidráulicos. G.O. Ordinaria No.14. (11-5-1995)

- Decreto No. 205. Preparación de la economía para la Defensa. G.O. Ordinaria No.14 (2-5-1996).

- Decreto No. 211. Contravenciones servicios acueducto y alcantarillado. G.O. Ordinaria No.34 (18-10-1996).

- Decreto No. 222. Reglamento de la Ley de Minas. G.O. Ordinaria No.32. (19-9-1997).

- Decreto No. 228. Contravenciones personales en materia de Auditoría. G.O. Ordinaria No.37. (24-11-1997).

- Decreto No. 272. Contravenciones en materia ordenamiento territorial y de urbanismo. G.O. Extraordinaria No.2.(21-22001).

- Decreto No. 274. Reglamento de la Ley de Puertos. G.O. Ordinaria No.23. (27-7- 2003).

- Resolución No. 4. (18-06-2001). Ministerio de auditoría y control. Registro de auditores.

- Resolución No. 60. Contraloría General de la República de Cuba.

- Instrucción No. 161 del 2000. TSP. Competencia Sala Económico Tribunal Popular en conocer los conflictos del medio ambientales

- Instrucción No. 4 (1998). Metodología aplicación de las Contravenciones Personales. Ministerio de Finanzas y Precios.

Materiales digitales, artículos, tesis y revistas consultadas:

- - (2009). La jurisdicción de la auditoría ambiental: una herramienta de gestión en la protección medioambiental. Profesor asistente carrera derecho. Universidad de Granma. Cuba. 
- Álvarez-Salgado, R. (2011). Tesis de Licenciado en Derecho. Los instrumentos de gestión ambiental. Universidad de Granma. Facultad de Ciencias Sociales y Humanísticas.

- Ander-Egg, E. (s.f.). El desafío ecológico. Humanitas. Buenos Aires. Argentina.

- Antúnez-Sánchez, A. (2003). Papel del Jurista en la Auditoría Gubernamental en la Provincia Granma. (Auditoría de Cumplimiento). Tesina Diplomatura en Derecho Empresarial. Universidad de Oriente. Ministerio de Auditoría y Control. Granma.

- Fernández de Gatta Sánchez, D. (s.f.). Tesis el surgimiento de la problemática ambiental. Profesor titular de derecho administrativo. Universidad de Salamanca. España. Diplomado en ciencias ambientales.

- Fernández Paz, J. (1990). "Las Contravenciones" Revista Jurídica No. 26. MINJUS.

- Finanzas al Día: Colección Legislativa, divulgación Sistema de contravenciones y procedimientos administrativos.(1987). Tomos I y II. Editora Ministerio de Finanzas y Precios. Cuba.

- Hernández-Torres, V. (2000). "Legislación ambiental cubana. ¿Un enfoque sistémico?” Revista Jurídica MINJUS No. 1: La Habana.

- Méndez-Delgado, E., et al. (s.f). Globalización: interrogantes y dimensiones. Universidad de Las Villas.

- Milán P., et al. (s.f.) Principios ambientales básicos. Maestría en derecho agrario. UH.

- Pérez -Kasparian, S. (1992). "La ecología y el derecho penal cubano". Revista Cubana de Derecho No. 8. Editora UNJC. La Habana.

- Pichs-Madruga, R. (2008). Cambio climático. Globalización y subdesarrollo. Editora Científico Técnica. La Habana.

- Pita-Jiménez, N. (s.f.). Tesis especialidad en derecho civil y familia. Universidad de Oriente. Facultad de derecho. Santiago de Cuba. República de Cuba.

- Revista Jurídica No. 20. (1988). MINJUS. "Perspectiva filosófica del cuidado del medio ambiente y su relación con el sistema de derecho en Cuba".

- Trujillo-Hernández, C. (s.f.) Medio ambiente y constitución.

\section{Manuales y metodologías en materia de formación en medio} ambiente consultados:

- Aguilar, G., et al. (2004). Manual de derecho ambiental en Centroamérica. Editora: Unión Mundial de la Naturaleza. Centro de derecho ambiental de la Unión Mundial por la naturaleza. Costa Rica. Consultado 27 de febrero 2012.

- Bustos Ayoví, F. (s.f.). Manual de gestión y control ambiental. ISBN 9978-41-832-6. Impreso en Ecuador. Consultado el 14 de febrero 2012. 
- CITMA. (1998). Metodología para el aprovechamiento económico de los residuales: Editora CITMA. Cuba.

- CITMA. (1998). Metodología para la evaluación aproximada de las cargas contaminantes en las cuencas hidrográficas cubanas: Editora CITMA. Cuba.

- Manual de derecho ambiental en Centroamérica. (s.f.). Editora: Centro de derecho ambiental de la unión mundial por la naturaleza. San José. Costa Rica. Consultado el 17 de junio 2011.

- Manual del Auditor (2002). Ministerio de Auditoría y Control. Cuba.

- Manual del ciudadano ambiental. (s.f). Consultado el 27 de febrero 2012.

- Viña-Vizcaíno, G. (s.f.). Manual introductorio: bases conceptuales de la auditoría ambiental como un instrumento en la prevención de la contaminación. Director sectorial Ministerio del Medio Ambiente. Bogotá. Colombia. Consultado el 14 de febrero 2012.

\section{Bibliografía electrónica consultada:}

- Álvarez-Álvarez, Jorge., et al. (2009). Elementos básicos para el trabajo del inspector ambiental estatal. CITMA. La Habana. Cuba. Consultado el 27 de febrero 2012.

- Allende, José. (s.f.). Medio ambiente. Luces y sombras en el conflicto ambiental. España. Disponible en la Revista Ekonomiaz. Consultado el 14 de febrero 2012.

- Ander-Egg, E. (2002). El desafío ecológico. Revista Humanitas. Buenos Aires. Argentina. Consultado 27 de febrero 2012.

- Aristazabal-Ossa, Hugo. (s.f.). Curso de auditorías ambientales. La Contraloría General de Colombia. Consultado el 17 de junio de 2011.

- Armisén- Causarano, J. P. (2008). Concepto, alcances y resultados actuales. Consultado 27 de febrero 2012.

- BIFANI, P. (1997). Medio Ambiente y desarrollo. Universidad de Guadalajara, pp. 699. Consultado 27 de febrero 2012.

- Carmona-Lara, M del C. (s.f.). Derecho ecológico. Consultado 17 de junio 2011.

- Carmona-Lara, M. del C. (2003). Ley general del equilibrio ecológico y la protección al ambiente, comentarios y concordancias. Universidad Nacional Autónoma de México, primera edición, 2003. Consultado el 27 de febrero 2012.

- Carmona-Lara, M. del C. (s.f.). Notas para el análisis de la responsabilidad ambiental y el principio de quien contamina paga en el derecho mexicano. Consultado el 18 de junio 2011.

- Curso de derecho y medio ambiente. Universidad para todos. MES. La Habana. Cuba. Parte I y II. 
- Darío-Muriel, Rafael (s.f.). Orígenes de la Problemática Ambiental. [en línea] Obtenido desde : http://www. Ide@Sostenible.com/colmex/cap2.pdf. Consultado el 2 de abril de 2011.

- Del Moral Ituarte, L. (s.f.). Nuevos planteamientos científicos y participación ciudadana en la resolución de los conflictos ambientales. Universidad de Sevilla. España. Consultado 27 de febrero 2012.

- Demaldé, Cristina., et al. (s.f.). El principio de precaución en el daño ambiental. UNAM. México. Consultado en fecha 14 de febrero 2012.

- Escobar, L. \& Martínez, C. (s.f.). Auditoría Ambiental. Granada. España. Obtenido desde: http:/www.ar.ca.org/02.Trabajo sobre cultural ambiental. Fecha: 6/6/2004.

- Estrategia Catalana de Educación Ambiental. (s.f.). [En línea] Obtenido desde: http://www.gencat.es. [Consultado el 7 de mayo de 2010].

- Estudios de impacto y auditoría ambiental. España. IUSC. Departamento de Medio Ambiente Universidad de Cataluña España. Curso de Máster. Fecha: 7/7/2004

- Evaluación del Impacto Ambiental [en línea] [consultado el 23 de marzo de 2010].

- Evolución y tendencias de las auditorías ambientales. INTOSAI. (2007). Obtenido desde: www.enviromentalauditing.org. Consultado 27 de febrero 2012.

- Fernández de Gatta, D. (s.f.). Derecho ambiental. Aspectos generales sobre la protección jurídica del medio ambiente. Universidad de Salamanca. España. Consultado el 14 de febrero 2012.

- Fiscalía especializada para la atención de los delitos ambientales. Procuraduría General de Justicia del Estado. Córdova. Argentina. Consultado el 14 de febrero 2012.

- Font- Aranda, M., et al. (s.f.). La auditoría ambiental, una perspectiva global y nacional. Instituto de Turismo Matanzas. Universidad de Matanzas. Cuba. Consultado el 17 de junio 2011.

- Fundamentos de la auditoría ambiental. IEMA. EARA. Brasil. Normas ISO 1400-14001. Curso de auditoria ambiental. Fecha: 6/6/2004.

- Galeano-Rey, J. P. (s.f.). Gobernanza y gobernabilidad. Obtenido desde: «http://es. wikipedia.org/w/index.php?title=Gobernanza_ambie ntal\&oldid=53666249. » Consultado el 14 de febrero 2012.

- García-Martínez, M. Á. (s.f.). Cómo trabaja el Ministerio Público Ambiental en Costa Rica. Consultado el 24 de febrero 2012.

- Gestión Comunitaria. Obtenido desde: http://www.hidrolara.com.velindex.asp?spg_id=12. Consultado el 2 de mayo de 2010.

- Globalización del derecho ambiental. Consultado el 17 de junio 2011. 
- Glosario de términos y definiciones de uso frecuente en contaminación marina y medio ambiente acu.htm Consultado el 27 de febrero 2012.

- Gobernabilidad ambiental. Disponible en Wikipedia en español. Consultado el 14 de febrero 2012.

- Gobernanza ambiental. Wikipedia en español. Consultado el 14 de febrero 2012.

- González-Malaxechavarria, Á. (1997). Auditoría medioambiental, su evolución histórica y entorno políticoinstitucional. Instituto de Auditores Internos de España. Madrid. Consultado el 27 de febrero 2012.

- GOODLAND, R. \&, V.EDMUNDSON, V. (1994).Environmental assessment and development; The World Bank; Washington, D.C., 1994, pp. 113 Consultado el 27 de febrero 2012.

- Guía metodológica para la gestión comunitaria de los conflictos ambientales. Observatorio latinoamericano de conflictos ambientales. Chile. Consultado el 14 de febrero 2012

- Guzmán-Rosen, R., (2011). Apuntes sobre la existencia, concepto y contenido del derecho ambiental. Revista de derecho. Universidad de Concepción. No. 217- 2011. Consultado el 17 de junio 2011.

- Guzmán-Rosen, R. (s.f). Auditoría Ambiental. Colombia. Obtenido desde: http://wwwbolivia.industry.com/instgest/gestamb/audeur o.htm. Fecha: 6/6/2004. http://www.ine.gob.mx/ueajei/publicaciones/consultaPubl icacion.html?id_pub=255. Consultado el 27 de febrero 2012.

- Impacto Ambiental. [en línea] Obtenido desde: [consultado el 10 de abril de 2010]. Disponible en: http://www.ine.gob.mx/enautica/download_colmex/cap5. pdf. Consultado el 10 de abril de 2010.

- Iñiguez-Rojas, L. (1996). Lo socio-ambiental y el bienestar humano. Revista Cubana de Salud Pública. Consultado el 20 de julio 2011.

- Jerez-Argueta, María. (s.f.). Interacción del derecho administrativo y el derecho ambiental en la esfera disciplinaria de los particulares y estatales que trasgreden las leyes medioambientales. Guatemala. Consultado el 17 de junio 2011.

- Juste- Ruiz, J. (s.f.). La evolución del derecho internacional del medio ambiente. Revista Autonomies. Barcelona. España. Consultado el 27 de febrero 2012.

- La participación ciudadana en el sistema de evaluación del impacto ambiental chileno. Consultado el 27 de febrero 2012.

- LEÓN-PELÁEZ, J.D. (2002). La Evaluación Estratégica Ambiental (EAE): eje orientador de una planificación de mayor alcance; Gestión y Ambiente. Vol.5; No.1; pp. 61-73 Consultado el 27 de febrero 2012. 
- Libro verde la Unión Europea sobre responsabilidad social de las empresas. Consultado el 27 de febrero 2012.

- López-Menudo, F. (s.f.). El derecho a la protección del medio ambiente. Consultado 17 de junio 2011.

- Macías, L. F.; et al. (s.f.). Aspectos jurídicos de la participación ciudadana en la gestión ambiental. Autor: Macías, Luis Fernando. Macías/López\&Asociados. Consultado 24 de febrero 2012.

- Maes, F. (s.f.). Los principios del derecho ambiental, su naturaleza. Consultado 17 de junio 2011. Consultado 27 de febrero 2012.

- Márquez de Almeida, J. J. (s.f.). La problemática ambiental y la auditoría. Profesor Coordinador del Instituto Superior de Contabilidad y Administración de Coimbra. INSTITUTO SUPERIOR DE CONTABILIDADE E ADMINISTRAÇÃO DE COIMBRA. Portugal.Consultado el 27 de febrero 2012.

- Martínez de Anguita, P. (s.f.). Jerarquización de las decisiones ambientales. Disponible en la Revista Observatorio Medioambiental. Consultado el 14 de febrero 2012.

- Martínez, Z. I. (1996). Curso sobre Auditoria Ambiental; Seminario de Explotación Minera y Medio Ambiente.; CIMM., pp.24. Consultado 27 de febrero 2012.

- Medio Ambiente y Desarrollo Sostenible. [en línea].Obtenido desde: http://www.cinu.org.mx. Consultado el 7 de mayo de 2010.

- Morata, Francesc \& Kenneth, Hanf. (2000). La gobernación del medio ambiente. Cataluña. Universitat Pompeu Fabra. Institut de Ciències Polítiques i Socials. Barcelona. ISSN: 1133-8962. Imprenta: A.bis. Consultado el 27 de febrero 2012.

- Moreno-Muñoz, Miguel. (2010). "Justicia global y seguridad humana, en el contexto del cambio climático". Universidad de Granada. España. Tomado de la Revista de filosofía y moral política. No. 43. Consultado el 17 de junio 2011.

- Morris, S. (s.f.). Medio ambiente y ecología. Obtenido desde: http/l www.ambientum.com. httpwww.tierramerica.net20050115ecobreves.shtml.htm. 22/8/2004. Revista Ecobreves. httpwww.tierramerica.net20050115ecobreves.shtml.htm. Consultado 27 de febrero 2012.

- Navas-Escudero, C. (2008. ). Libro de Derecho Ambiental, compilación de artículos. Biblioteca Jurídica Virtual. UNAM. México. Consultado el 27 de febrero 2012.

- Negrao-Cavalcanti, Rachel. (s.f.). Gestión Ambiental. [en línea] Obtenido desde: http://www.Medio Ambiente.com. Consultado el 20 de marzo de 2011.

- Nicolo. G. (s.f.). La dimensión ambiental en el desarrollo de América Latina. Publicado en Revista de la CEPAL. Número 55. Chile. Consultado el 27 de febrero 2012.

- Pavo-Acosta, R., et al. (2003). Medio ambiente, Actividad Agropecuaria y Derecho en el Contexto Cubano Actual. 
Jornada Científica Facultad de Ciencias Naturales Editora del Departamento de información Científico Técnica. Universidad de Oriente. Santiago de Cuba. 2003. ISBN 959-207-903-8. Consultado el 27 de febrero 2012.

- B. Pereyra, B. ; Lic. A., et al. (2009). La dimensión social de la EIA. De la teoría a la realidad. Autoras: Universidad Nacional de Lujan. Buenos Aires. Argentina. Consultado el 27 de febrero 2012.

- Prado-Carrera, G. (s.f.). Evolución del derecho ambiental. Consultado 17 de junio 2011.

- Principios de la Cultura Ambiental Empresarial. [en línea] Obtenido desde: http: //www.geml.org.mx. Consultado el 7 de mayo de 2010.

- Ramos-Hernández, Y. et al. (s.f.). Consideraciones sobre la evaluación del impacto ambiental en Cuba. Consultado 17 de junio 2011.

- Rojas, A., et al. (s.f.). Conflictos ambientales en Chile: aprendizajes y desafíos. Disponible en: la Revista ambiente $y$ desarrollo del CIPMA. Chile. Obtenido desde: www.cipma.cl, www.iepe.org. Consultado el16 de febrero 2012.

- Rubio- Legra, Á. (s.f.) El derecho ambiental en los estados Unidos. ECURED. Profesor Titular del ISRI. Cuba. Consultado 17 de junio 2011.

- Sabatini, F. (s.f.). Espiral histórica de los conflictos ambientales: el caso Chile. Profesor del Instituto de estudios urbanos de la Universidad Pontificia Universidad Católica de Chile. Disponible en la revista ambiente y desarrollo. Consultado el 14 de febrero 2012.

- Sepúlveda, C. (1999). Recomendaciones a partir de una percepción ciudadana: ¿Cómo fortalecer la prevención de conflictos en el SEIA? Socióloga. Magister en asentamientos humanos y medio ambiente. CIPMA. Universidad Católica de Chile. Revista ambiente y desarrollo. Volumen XV. ISSN 0716-1476. Consultado el 14 de febrero 2012. Chile.

- Sistema de Evaluación del Impacto Ambiental. [en línea] Obtenido desde: http://eurlex.europa.eu/LexUriServ/siteles/com/2000/com2000_059 0es08.pdf. Consultado el 27 de febrero de 2010.

- Sistema de Gestión Ambiental. [en línea] Obtenido desde: http://www2.ine.gob.mx/publicaciones/libros/398/delosrio s.html. Consultado el 2 de mayo de 2010.

- Vallejos- Romero, A. (s.f.). Los conflictos ambientales en una sociedad mundializada. Antecedentes y consideraciones para Chile. Profesor de la Universidad Latinoamericana de Ciencias Sociales. FLACSO. México. Consultado el 14 de febrero 2012.

- Velásquez-Muñoz, J. (2004). Conciliación de conflictos ambientales. Abogado Universidad del Norte. Especialista en derecho ambiental. Revista de derecho. Universidad del Norte. Número 21. Colombia. 
- Weterskov, Kim (s.f.). Protección al medio ambiente. Obtenido desde: http// www.foe.org. Consultado el $11 / 11 / 2004$.

1. M.Sc. Profesor Derecho ambiental y mercantil. Carrera de derecho. Facultad de Ciencias Sociales y Humanísticas. Universidad de Granma. República de Cuba. Email: aantunez@udg.co.cu

2. M.Sc. Profesor Derecho internacional y Teoría del Derecho. Carrera de derecho. Facultad de Ciencias Sociales y Humanísticas. Universidad de Granma. República de Cuba. Email: cbruzonv@udg.co.cu 